Universidad de Lima

Facultad de Comunicación

Carrera de Comunicación

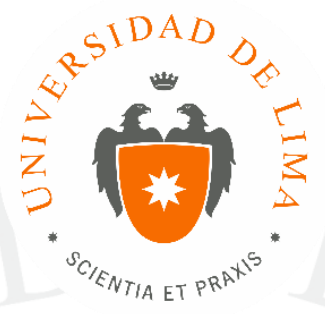

\title{
MADRES MÁS FUERTES
}

Trabajo de Suficiencia Profesional para optar el Título Profesional de Licenciado en Comunicación

\section{Nancy Claudia Cecilia Tapia Huambachano}

Código 20072620

$$
\text { Lima - Perú }
$$

Septiembre de 2018 


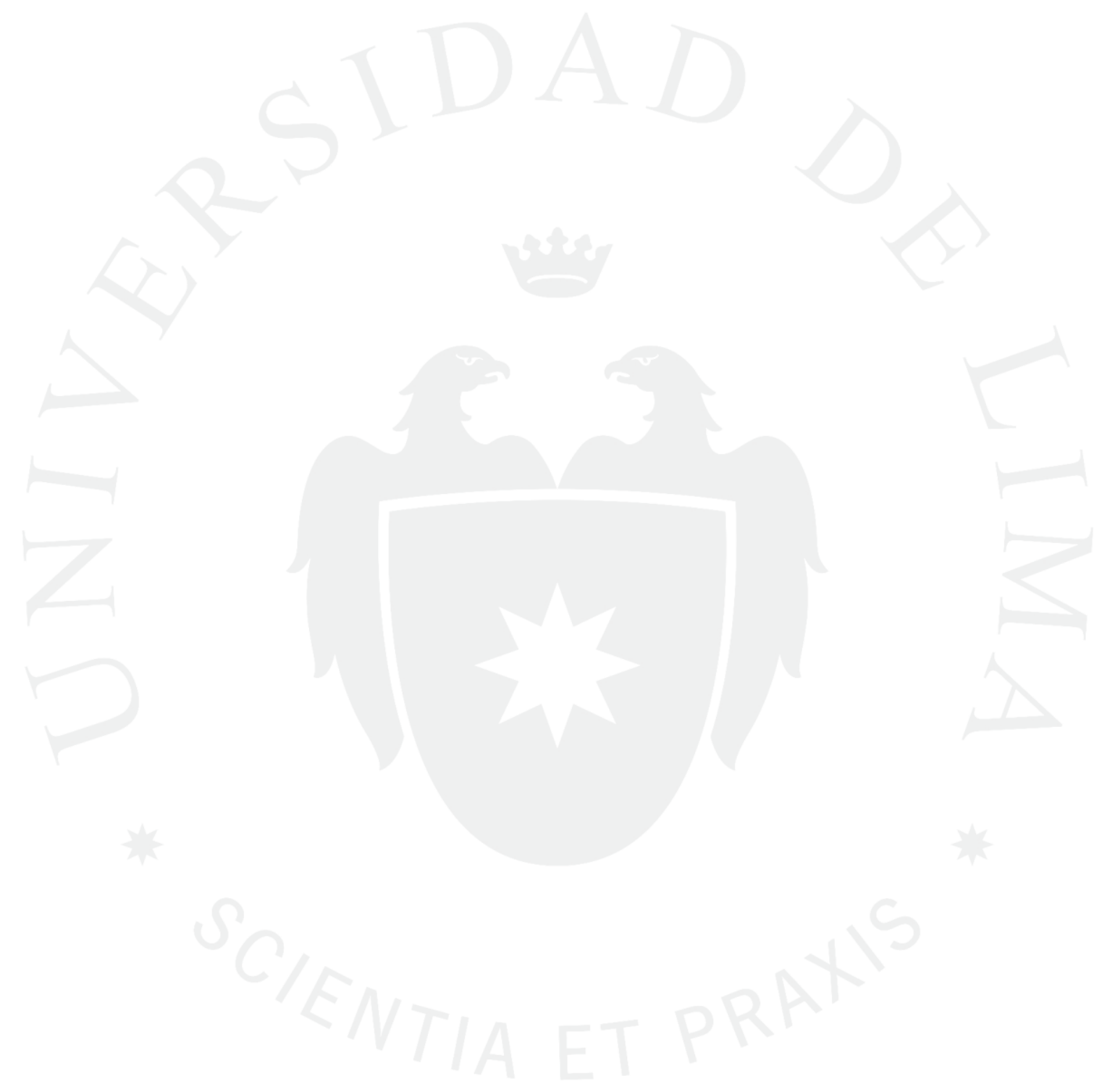




\section{MADRES MÁS FUERTES}




\section{ÍNDICE}

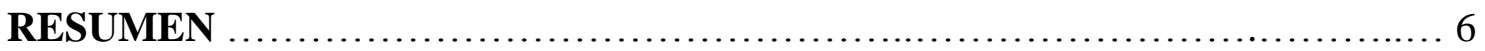

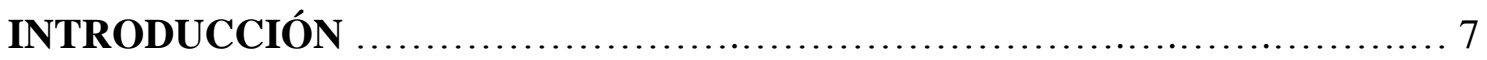

1. CAPITULO I: PLANEAMIENTO DEL ESTUDIO ............................. 8

1.1 Situación de la Problemática...............................................8

1.1.1 Mortalidad Materna en el Perú......................................... 9

1.1.2 Público Objetivo.................................................... 14

1.1.3 Ámbito de trabajo ............................................. 15

1.1.4 Organismo: Cáritas del Perú........................................19

2. CAPITULO II: ESTRATEGIA DE COMUNICACIÓN........................ 21

2.1 Herramientas de Comunicación........................................ 21

2.1.1 Objetivos..................................................... 22

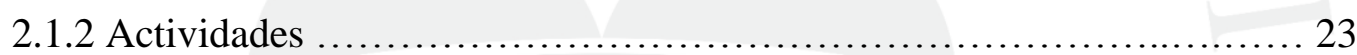

3. CAPITULO III: CONCEPTO CREATIVO ................................ 25

3.1 Campaña...................................................... 25

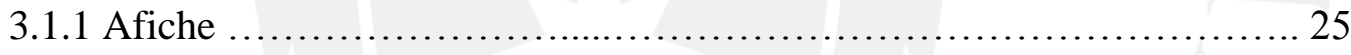

3.1.2 Volante ......................................................... 25

3.1.3 Spot Radial.................................................... 26

3.1.4 Post ............................................................. 26

3.1.5 Video .............................................................. 26

3.2 Estrategia de Contenidos ......................................... 27

3.3 Plan de Medios .................................................... 30

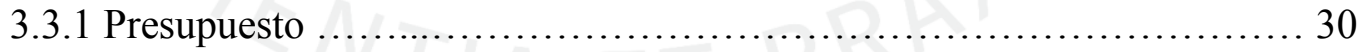

3.3.2 Cronograma de actividades.................................... 31

4 CAPITULO VI: EVALUACIÓN ........................................... 32

4.1 Plan de Evaluación .......................................................... 32

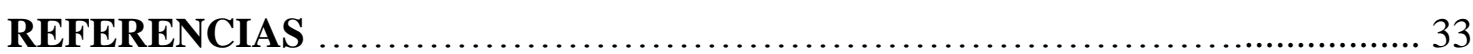

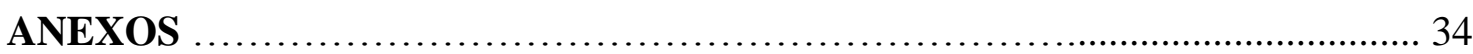

Anexo 1. Causa básica de muerte materna clasificada como directa, año 2015 ........ 35

Anexo 2. Causa básica de muerte materna clasificada como indirecta, año 2015 ..... 37 
Anexo 3. Entrevista al Dr.Luis Danckers Peralta, Ginecólogo-Obstetra-INPPARES... 39

Anexo 4. Mortalidad materna y población estimada por sexo, a nivel distrital en el departamento de Piura

Anexo 5. Ficha de control 42 


\section{ÍNDICE DE FIGURAS}

Figura 1.1 Número de muertes maternas Perú 2000-2018 .................... 10

Figura 1.2 Muerte materna según clasificación preliminar..................... 11

Figura 1.3 Muertes maternas según grupo de edad. Perú 2013-2018 ............. 12

Figura 1.4 Muerte materna según departamento de ocurrencia y procedencia

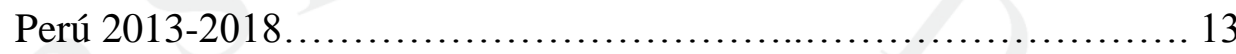

Figura 1.5 Muerte materna según condición al momento de muerte, año 2017 ... 16

Figura 1.6 Muerte materna según tipo de causa, año 2017 ...................... 16

Figura 1.7 Región Piura: muertes maternas según causa, año 2017 ...............17

Figura 1.8 Mapa distrital de muerte materna 2017. Región Piura .................. 18

Figura 1.9 Red de Cáritas Diocesanas ................................... 19

Figura 3.1 Radios FM en Piura ........................................ 28

Figura 3.2 Estadística de publicaciones destacadas en Facebook ................. 29 


\section{RESUMEN}

El presente trabajo, fue desarrollado con el propósito de contribuir con la sensibilización y concientización de la salud y nutrición de las madres gestantes del distrito de Huancabamba, provincia de Huancabamba, departamento de Piura, a manera de aportar con la reducción de la mortalidad materna en el Perú.

El índice de mortalidad materna en nuestro país se ha reducido en los últimos cinco años; sin embargo, es necesario que el Estado en coordinación con la sociedad civil realice un trabajo eficaz y eficiente relacionado a este tema de salud. El Perú, como miembro de los países firmantes de la Declaración del Milenio, tiene un gran compromiso tal como se establece en el Quinto Objetivo de Desarrollo del Milenio.

Es importante mencionar que este documento, contiene información estadística proporcionada por diversas instituciones y organismos, los cuales se hacen referencia con la finalidad de proponer una estrategia de comunicación basada en datos reales.

Personalmente, considero que la mortalidad materna en el Perú es un tema de gran importancia porque no sólo implica riesgos en la vida de la madre sino también en la vida del niño o niña por nacer. 


\section{INTRODUCCIÓN}

La mortalidad materna es un problema de salud a nivel mundial, que guarda relación directamente con la educación, situación de pobreza, acceso inadecuado al sistema de salud y habitan en zonas alejadas.

En lo que respecta a nuestro país, el Estado está comprometido con la reducción de la tasa de la mortalidad materna.

Este trabajo se ha realizado con la finalidad de proponer una campaña social en beneficio de personas vulnerables, que cuentan con menos acceso a la información y viven en situación de pobreza.

El primer capítulo de este documento, abarca la situación de la problemática a nivel mundial y a nivel social para luego tratar sobre la perspectiva de la organización que encabezará esta campaña.

En el segundo capítulo, se conocerá sobre las herramientas de comunicación que se utilizarán para la campaña, así como el público objetivo.

Continuando con el tercer capítulo, se propondrá el concepto creativo, especificándose el nombre de la campaña y las piezas que se realizarán a detalle. Se presentará también el plan de medios que contendrá información sobre el objetivo de la campaña y las actividades a realizar.

El cuarto capítulo se refiere a la medición de objetivos a manera de evaluar los resultados de la campaña social. 


\section{CAPÍTULO I: PLANTEAMIENTO DEL ESTUDIO}

\subsection{Situación de la problemática}

La mortalidad materna es la muerte de una mujer durante la etapa del embarazo, el parto o el puerperio (42 días después del parto); de acuerdo a información proporcionada por la Organización Mundial de la Salud - OMS, cada día mueren aproximadamente 830 (Organización Mundial de la Salud, 2018) mujeres por complicaciones relacionadas con el embarazo o el parto en todo el mundo.

Según lo referido por el Ministerio de la Salud, la mortalidad materna a nivel mundial, se encuentra relacionada a la situación de pobreza, desnutrición, analfabetismo, malas condiciones ambientales, servicios de salud insuficientes, difícil acceso a los servicios de salud, entre otros; es decir, que no es sólo un problema relacionado a la medicina, sino también un problema social que va de la mano al contexto de una población determinada. Cabe indicar, que muchas de las causas de las muertes maternas son ampliamente conocidas y podrían ser evitadas si se aplican mejores procedimientos y atenciones médicas a las gestantes. (Ministerio de Salud).

La Organización Mundial de la Salud - OMS, también afirma que la muerte materna es mayor en zonas rurales y en las comunidades más pobres. No es sólo un problema médico, sino que guarda relación con aspectos sociales, culturales, así como conocer a profundidad e interpretar el contexto en que viven las gestantes y no sólo conocer cifras. Asimismo, los factores que impiden que las gestantes reciban o busquen por su cuenta una buena atención médica son: la pobreza, la distancia, falta de información, falta de servicios adecuados y prácticas culturales, ya que con una adecuada atención antes, durante y después del parto se puede salvar la vida de las gestantes y los recién nacidos. (Organización Mundial de la Salud, 2018).

El control durante el embarazo es de vital importancia tanto para la salud de la madre como del hijo; la madre gestante debe ser examinada y evaluada para detectar situaciones de peligro en su salud y aconsejarla sobre la alimentación durante el embarazo, los síntomas y signos de posibles complicaciones del parto. (INEI, 2017)

La mortalidad materna viene a ser un problema muy agudo de salud, además de ser un problema ligado al ejercicio de derechos y a las condiciones de vida de un país. 
Muchas de las mujeres que fallecen y son parte de las estadísticas de mortalidad materna, presentan enfermedades que aparecen en la madre antes del embarazo pero que se agravan durante este, generando complicaciones que se producen en el embarazo y postparto, lo que las lleva a la muerte.

Existen tres tipos de muerte materna, a saber: muerte materna directa, indirecta e incidental.

La muerte materna directa, es aquella que se produce como consecuencia de complicaciones obstétricas del embarazo, parto o puerperio, intervenciones, complicaciones de la anestesia o tratamientos incorrectos.

La muerte materna indirecta, no proviene directamente a una causa obstétrica, sino de una enfermedad que ya existía en la madre o que apareció durante el embarazo pero se agravó por efectos propios, estas enfermedades suelen ser la tuberculosis, apendicitis, diabetes, entre otros.

La muerte materna incidental, es aquella que no está relacionada con el embarazo, parto o puerperio, ni con una enfermedad de la madre, sino que es producida por causas accidentales como asfixia, ahogamiento, accidentes de tránsito, etc. ( Ministerio de Salud, 2018).

\subsubsection{Mortalidad Materna en el Perú}

El Estado peruano ha desarrollado esfuerzos en los ocho Objetivos de Desarrollo del Milenio (ODM), los cuales fueron establecidos por dirigentes del mundo en la Cumbre del Milenio convocada por las Naciones Unidas en el año 2000. Nuestro país ha reforzado sus compromisos en las principales políticas y estrategias de desarrollo. Dentro de este marco, la mortalidad materna se encuentra en el objetivo cinco (ODM 5: Mejorar la salud materna). (UNESCO, 2017).

En la Figura 1.1, el Perú según cifras del Centro Nacional de Epidemiología del Ministerio de Salud, muestra que la mortalidad materna pasó de 383 defunciones en el año 2013 a 375 en el 2017, lo que representa una disminución de $2.1 \%$ en un periodo de cinco años. ( Ministerio de Salud, 2018). Este porcentaje refleja la ardua labor que corresponde realizar para mejor de la salud de las mujeres durante el embarazo, parto y postparto. Perú continúa siendo uno de los países de la región con una tasa de mortalidad materna más alta. 
Figura 1.1

Número de muertes maternas Perú 2000-2018

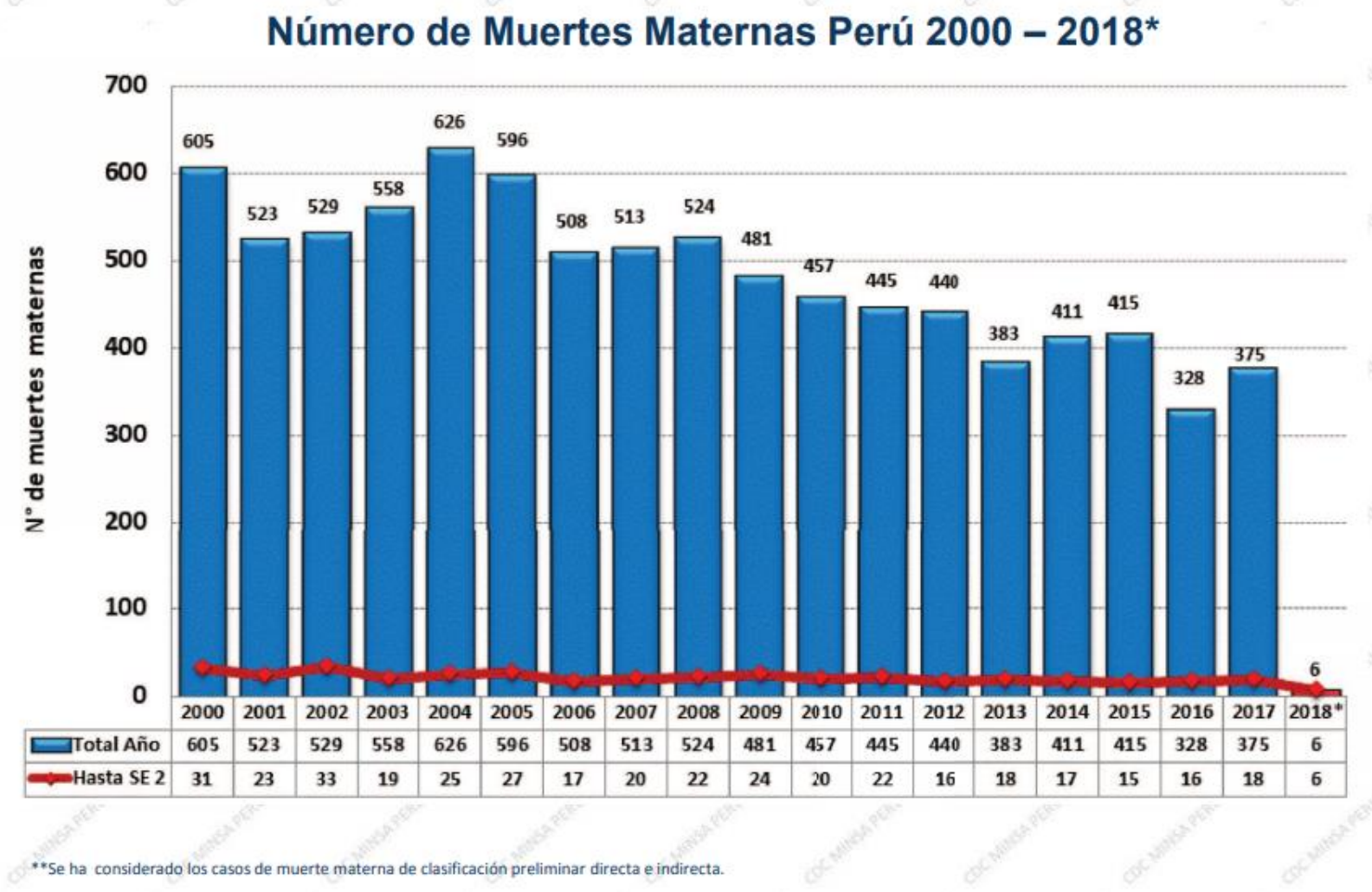

FUENTE : Centro Nacional de Epidemiologia, Prevención y Control de Enfermedades - MINSA (*) Hasta la SE 02 del 2018

En el mismo estudio y en la Figura 1.2 se observa que a nivel nacional, en el año 2013 el porcentaje de muerte materna directa era de 57.9\%, muerte materna indirecta era de 36.8\% y muerte materna incidental del 5,3\%; para el año 2017 el porcentaje de muerte materna directa fue de $61.1 \%$, muerte indirecta fue del $38.9 \%$ e incidental del $0.0 \%$. Ello indica que el porcentaje más alto en muertes se produce a causa de las muertes maternas directas; es decir tras complicaciones del embarazo, parto o postparto, intervenciones o tratamientos incorrectos que se le realiza a la madre. 
Figura 1.2

Muerte materna según clasificación preliminar

\section{Muerte Materna según clasificación preliminar}

a la SE 2, 2013-2018

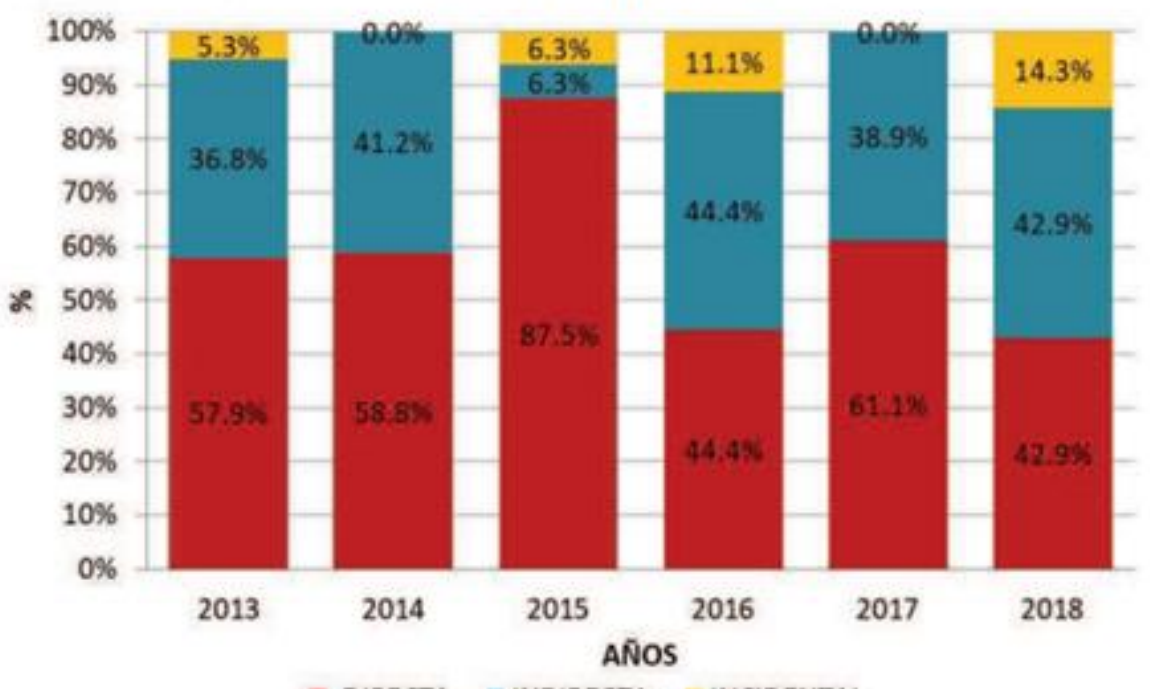

= DIRECTA =INDIRECTA =INCIDENTAL

* Se ha considerado los casos de muerte materna de clasificación preliminar directa , indirecta e incidental.

Fuente: Centro Nacional de Epidemiología, Prevención y Control de enfermedades - MINSA.

En la Figura 1.3, se describen los porcentajes de muerte materna en el Perú según grupos de edad. En el año 2013, el 8.9\% corresponde a casos de muertes maternas en mujeres menores de 19 años, el $65.3 \%$ corresponde a mujeres entre 20 y 35 años y el $25.8 \%$ a mujeres entre $\operatorname{los} 35$ y 50 años. Para el año 2017, el 16\% corresponde a casos de muertes maternas en mujeres menores de 19 años, el $62.7 \%$ corresponde a mujeres entre 20 y 35 años y el $21.3 \%$ a mujeres entre los 35 y 50 años. ( Ministerio de Salud, 2018). 
Figura 1.3

Muertes maternas según grupo de edad. Perú 2013-2018

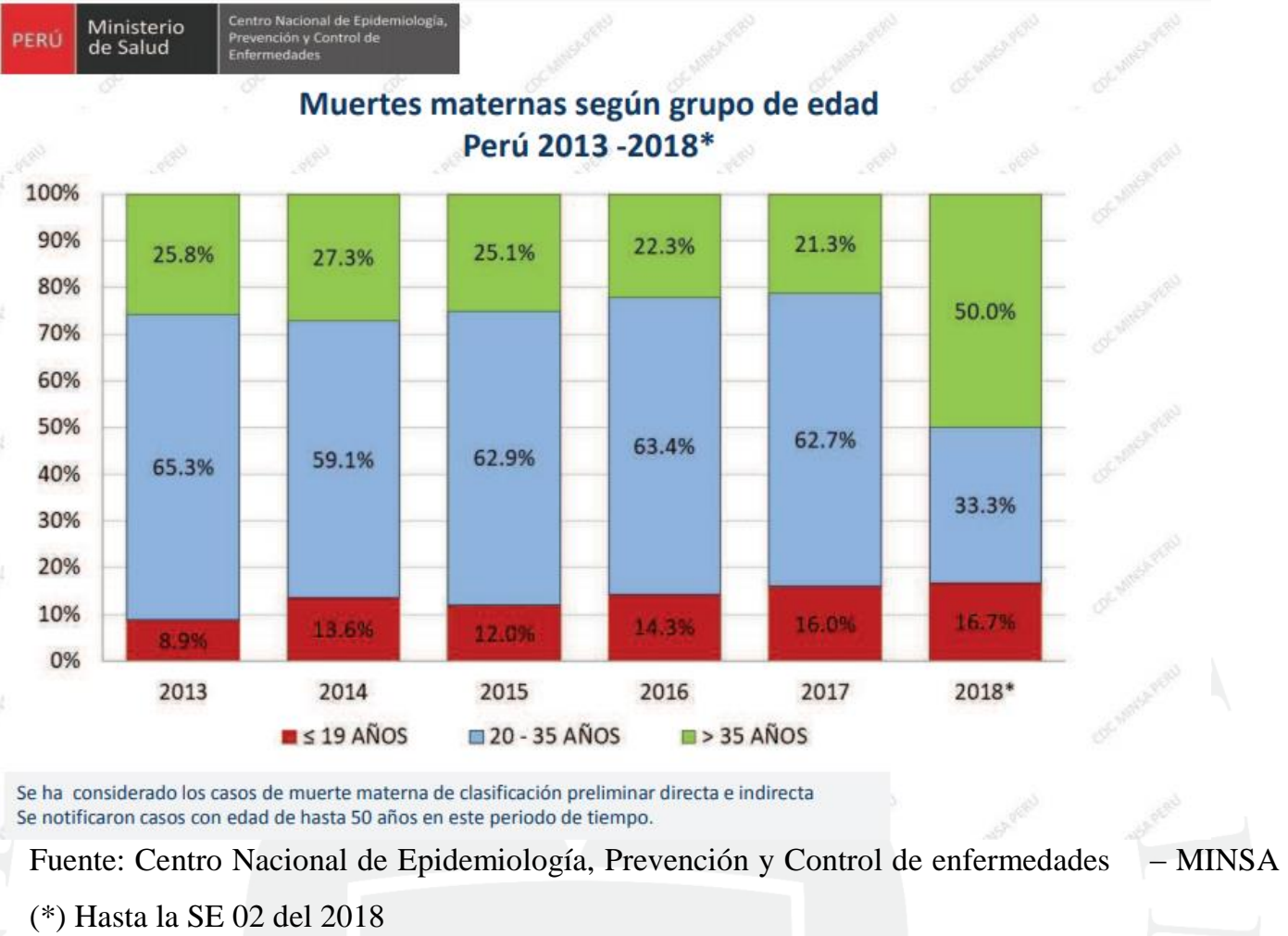

En la Figura 1.4 se muestran los casos de muerte materna según departamento de ocurrencia en el Perú. Para el año 2013, Lima tuvo 54 casos, seguido de La Libertad con 31, Piura presentó 30 y Loreto tuvo 29. En lo correspondiente al año 2017, Lima tuvo 51 casos, seguido de Piura con 36, Loreto presentó 34 al igual que La Libertad. Cabe mencionar que Piura fue la segunda región con mayor número de muertes maternas, registrando 170 casos, seguido de Lima con 285. ( Ministerio de Salud, 2018).

Asimismo, la Figura 1.4 muestra los casos de muerte materna según departamento de procedencia en el Perú. Para el año 2013, Lima tuvo 47 casos, seguido de Loreto con 32, Cajamarca con 31, La Libertad con 30 y Piura con 27. Para el año 2017, Loreto registró 40 casos, seguido de Lima con 36, Piura con 35, Cajamarca con 33, Puno y Cusco con 26. Cabe indicar que Piura fue la segunda región con mayor número de casos de muerte materna registrando 167, seguido de Lima con 228. ( Ministerio de Salud, 2018). 
Figura 1.4

Muerte materna según departamento de ocurrencia y procedencia Perú 2013-2018

PERÚ $\begin{aligned} & \text { Ministerio } \\ & \text { de Salud }\end{aligned}$

Muerte Materna según departamento de ocurrencia y procedencia Perú 2013 - 2018*

\begin{tabular}{|c|c|c|c|c|c|c|c|c|c|}
\hline \multirow{2}{*}{$\begin{array}{l}\text { DEPARTAMENTOS DE } \\
\text { OCURRENCIA } \\
\end{array}$} & \multicolumn{6}{|c|}{ ANNOS } & \multirow{2}{*}{ TOTAL } & \multirow{2}{*}{$\%$} & \multirow{2}{*}{ \% Acun. } \\
\hline & 2013 & 2014 & 2015 & 2016 & 2017 & $2018^{*}$ & & & \\
\hline AMAZONAS & 11 & 11 & 12 & 17 & 12 & 0 & 63 & 3.28 & 3.28 \\
\hline ANCASH & 14 & 14 & 12 & 14 & 8 & 0 & 62 & 3.23 & 6.52 \\
\hline APURIMAC & 1 & 2 & 4 & 3 & 1 & 0 & 11 & 0.57 & 7.09 \\
\hline AREQUIPA & 12 & 11 & 11 & 14 & 8 & 0 & 56 & 2.92 & 10.01 \\
\hline AYACUCHO & 7 & 10 & 8 & 6 & 8 & 0 & 39 & 2.03 & 12.04 \\
\hline CAJAMARCA & 29 & 30 & 31 & 22 & 31 & 0 & 143 & 7.46 & 19.50 \\
\hline CALLAO & 12 & 18 & 9 & 7 & 6 & 0 & 52 & 2.71 & 22.21 \\
\hline cusco & 23 & 29 & 18 & 22 & 26 & 0 & 118 & 6.15 & 28.36 \\
\hline HUANCAVELICA & 2 & 6 & 4 & 2 & 9 & 0 & 23 & 1.20 & 29.56 \\
\hline HUÁNUCO & 10 & 8 & 14 & 10 & 14 & 0 & 56 & 2.92 & 32.48 \\
\hline ICA & 6 & 4 & 4 & 3 & 4 & 0 & 21 & 1.09 & 33.58 \\
\hline JUNiN & 16 & 30 & 26 & 11 & 19 & 0 & 102 & 5.32 & 38.89 \\
\hline LA LIBERTAD & 31 & 30 & 28 & 25 & 23 & 1 & 138 & 7.19 & 46.09 \\
\hline LAMBAYEQUE & 19 & 23 & 24 & 15 & 17 & 0 & 98 & 5.11 & 51.20 \\
\hline LIMA & 54 & 51 & 74 & 55 & 51 & 1 & 286 & 14.91 & 66.11 \\
\hline LORETO & 29 & 32 & 25 & 24 & 34 & 1 & 145 & 7.56 & 73.67 \\
\hline MADRE DE DIOS & 5 & 3 & 2 & 2 & 2 & 0 & 14 & 0.73 & 74.40 \\
\hline MOQUEGUA & 1 & 0 & 1 & 0 & 0 & 0 & 2 & 0.10 & 74.50 \\
\hline PASCO & 6 & 5 & 2 & 1 & 6 & 1 & 21 & 1.09 & 75.60 \\
\hline PIURA & 30 & 28 & 42 & 34 & 36 & 0 & 170 & 8.86 & 84.46 \\
\hline PUNO & 25 & 25 & 28 & 13 & 25 & 2 & 118 & 6.15 & 90.62 \\
\hline SAN MARTIN & 18 & 13 & 14 & 8 & 18 & 0 & 71 & 3.70 & 94.32 \\
\hline TACNA & 5 & 1 & 2 & 7 & 3 & 0 & 18 & 0.94 & 95.26 \\
\hline TUMBES & 2 & 3 & 2 & 2 & 1 & 0 & 10 & 0.52 & 95.78 \\
\hline UCAYALI & 15 & 24 & 18 & 11 & 13 & 0 & 81 & 4.22 & 100.00 \\
\hline Total general & 383 & 411 & 415 & 328 & 375 & 6 & 1918 & 100 & \\
\hline
\end{tabular}

\begin{tabular}{|c|c|c|c|c|c|c|c|c|c|}
\hline \multirow{2}{*}{$\begin{array}{l}\text { DEPARTAMENTOS } \\
\text { DE PROCEDENCIA }\end{array}$} & \multicolumn{6}{|c|}{ ANNOS } & \multirow[b]{2}{*}{ TOTAL } & \multirow[b]{2}{*}{$\%$} & \multirow{2}{*}{$\%$ Acun } \\
\hline & 2013 & 2014 & 2015 & 2016 & 2017 & $2018^{*}$ & & & \\
\hline AMAZONAS & 13 & 13 & 13 & 19 & 13 & 0 & 71 & 3.70 & 3.70 \\
\hline ANCASH & 16 & 15 & 16 & 15 & 12 & 0 & 74 & 3.86 & 7.56 \\
\hline APURIMAC & 2 & 3 & 4 & 3 & 2 & 0 & 14 & 0.73 & 8.29 \\
\hline AREQUIPA & 9 & 10 & 11 & 13 & 6 & 0 & 49 & 2.55 & 10.84 \\
\hline AYACUCHO & 8 & 10 & 5 & 8 & 8 & 0 & 39 & 2.03 & 12.88 \\
\hline CAJAMARCA & 31 & 36 & 38 & 21 & 33 & 1 & 160 & 8.34 & 21.22 \\
\hline CALLAO & 13 & 19 & 10 & 7 & 7 & 0 & 56 & 2.92 & 24.14 \\
\hline cusco & 20 & 30 & 19 & 21 & 26 & 0 & 116 & 6.05 & 30.19 \\
\hline HUANCAVELICA & 6 & 8 & 6 & 3 & 13 & 0 & 36 & 1.88 & 32.06 \\
\hline HUANUCO & 11 & 9 & 18 & 13 & 17 & 0 & 68 & 3.55 & 35.61 \\
\hline ICA & 6 & 3 & 5 & 2 & 5 & 0 & 21 & 1.09 & 36.70 \\
\hline JUNIN & 17 & 26 & 27 & 11 & 15 & 0 & 96 & 5.01 & 41.71 \\
\hline LA LIBERTAD & 30 & 31 & 29 & 26 & 23 & 0 & 139 & 7.25 & 48.96 \\
\hline LAMBAYEQUE & 14 & 13 & 16 & 15 & 12 & 0 & 70 & 3.65 & 52.61 \\
\hline LIMA & 47 & 42 & 58 & 45 & 36 & 1 & 229 & 11.94 & 64.55 \\
\hline LORETO & 32 & 32 & 27 & 24 & 40 & 1 & 156 & 8.13 & 72.68 \\
\hline MADRE DE DIOS & 7 & 3 & 2 & 3 & 3 & 0 & 18 & 0.94 & 73.62 \\
\hline MOQUEGUA & 3 & 0 & 1 & 2 & 1 & 0 & 7 & 0.36 & 73.98 \\
\hline PASCO & 5 & 11 & 4 & 5 & 8 & 1 & 34 & 1.77 & 75.76 \\
\hline PIURA & 27 & 29 & 41 & 35 & 35 & 0 & 167 & 8.71 & 84.46 \\
\hline PUNO & 26 & 26 & 28 & 13 & 26 & 2 & 121 & 6.31 & 90.77 \\
\hline SAN MARTIN & 16 & 16 & 14 & 8 & 18 & 0 & 72 & 3.75 & 94.53 \\
\hline TACNA & 5 & 1 & 2 & 7 & 3 & 0 & 18 & 0.94 & 95.46 \\
\hline TUMBES & 5 & 2 & 4 & 2 & 2 & 0 & 15 & 0.78 & 96.25 \\
\hline UCAYALI & 14 & 23 & 17 & 7 & 11 & 0 & 72 & 3.75 & 100.00 \\
\hline Total general & 383 & 411 & 415 & 328 & 375 & 6 & 1918 & 100 & \\
\hline
\end{tabular}

Se ha considerado los casos de muerte materna de

Ocurrencia: Departamento/región donde se produjo la muerte y que notifica el caso.

Procedencia: Departamento/región de residencia de forma permanente de la fallecida en los últimos doce meses, o la mayor parte del tiempo de ese período.

Fuente: Centro Nacional de Epidemiología, Prevención y Control de enfermedades - MINSA

(*) Hasta la SE 02 del 2018

De acuerdo a un estudio realizado en enero del 2016 por el Centro Nacional de Epidemiología, Prevención y Control de Enfermedades del Ministerio de Salud, las principales causas de muerte materna de tipo directa en el Perú se deben a hemorragias que representa el $36.5 \%$, enfermedades hipertensivas del embarazo con 31.5\%, Sepsis con $21.5 \%$ y otros con $10.5 \%$ (Anexo 1) (Ministerio de Salud, 2016). 
En el mismo estudio se puede observar que las principales causas de muerte materna de tipo indirecta en el Perú, se deben a infecciones que representan el $24.4 \%$, lesiones autoinfligidas, violencia y trastornos de salud mental con $14.4 \%$, enfermedades cerebrovascular u otros del sistema nervioso con $13.3 . \%$, enfermedad cardiovascular con $12.2 \%$, tumores con $7.8 \%$, enfermedades endocrinológicas con $5.6 \%$, enfermedades del sistema digestivo con $4.4 \%$ y otros con 17.8\%. (Anexo 2) (Ministerio de Salud, 2016).

De acuerdo a la entrevista realizada al Ginecólgo Obstetra Dr. Luis Danckerz Peralta, del Instituto Peruano de Paternidad Responsable - Inppares, manifestó que la tasa de mortalidad materna ha mejorado en el Perú, pero que el $70 \%$ al $90 \%$ de esas muertes maternas podrían ser prevenibles. Asimismo, mencionó que en las zonas rurales la tasa es más elevada, siendo otra causa de ello que muchas mujeres no tiene control prenatal, otras tienen partos en casa y se encuentran en situación de pobreza. Es así, que recomienda como medida para la reducción de la mortalidad materna, una buena educación en la madre, un adecuado control prenatal y conocimiento de los factores de riesgo. (Anexo 3).

\subsubsection{Público Objetivo}

Para este trabajo, se ha identificado y segmentado el público objetivo en primario, secundario y aliados.

Para el público primario, se ha segmentado a mujeres gestantes del distrito de Huancabamba, provincia de Huancabamaba, región Piura.

Para el caso del público secundario, se ha identificado al esposo, pareja o familiar más cercano de la mujer gestante.

Como aliados, se cuenta con el apoyo de Cáritas Chulucanas, Cáritas Española, Municipalidad de Huancabamba y las educadoras comunales (EC) del distrito de Huancabamba:

- Cáritas Chulucanas:

Ejecutará un conjunto de estrategias planificadas por Cáritas del Perú para concientizar al público objetivo a través de las Educadoras Comunales (EC) y contribuir con la reducción de la mortalidad materna de las madres gestantes, 
producto de su amplia experiencia en proyectos ejecutados a nivel nacional, que han mostrado impacto, eficiencia en el uso de recursos, esquemas y mecanismos organizacionales internos y de relacionamiento interinstitucional y buen grado de participación social.

- Cáritas Española:

A través de su apoyo financiero, promoverá el desarrollo social enfocado en la salud de las mujeres gestantes del distrito de Huancabamba durante la ejecución de la campaña.

- Municipalidad Distrital de Huancabamba:

Brindará apoyo logístico para ejecutar gestiones eficientes, comprometiéndose con la población del distrito.

- Educadoras Comunales (EC):

Es una mujer de la comunidad, que habiendo sido capacitada es clave para el aprendizaje de las demás familias en lo referente a temas relacionados al adecuado cuidado de la salud durante la etapa del embarazo.

\subsection{3 Ámbito de trabajo}

Para el ámbito de trabajo se ha seleccionado a la región de Piura, ya que es el lugar que presenta mayor número de casos de muerte materna en el Perú, tal como se muestra en la Figura 1.4.

De acuerdo a la Figura 1.5 el porcentaje más alto de muerte materna en la región Piura es del $57 \%$ durante el puerperio, en la etapa de gestación con $40 \%$ y en el parto con 3\%. (DIRESAPIURA, 2017) 
Figura 1.5

Muerte materna según condición al momento de muerte, año 2017.

\section{MUERTE MATERNA SEGÚN CONDICION AL \\ MOMENTO DE MUERTE, AÑO 2017}

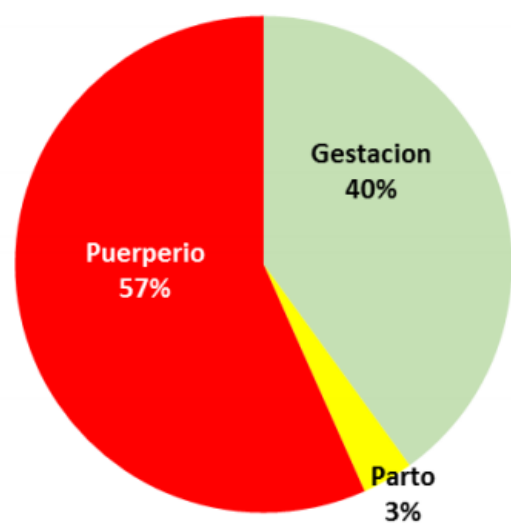

Fuente: Dirección Regional de Salud Piura, 2017

La Figura 1.6 muestra la distribución porcentual según el tipo de causa que origina la muerte materna en la región Piura, siendo el de mayor porcentaje la causa de tipo directo con $70 \%$, seguido del tipo indirecto con $27 \%$ e incidental con $3 \%$. (DIRESAPIURA, 2017).

Figura 1.6

Muerte materna según tipo de causa, año 2017

\section{MUERTE MATERNA SEGÚN TIPO DE CAUSA.}

AÑO 2017

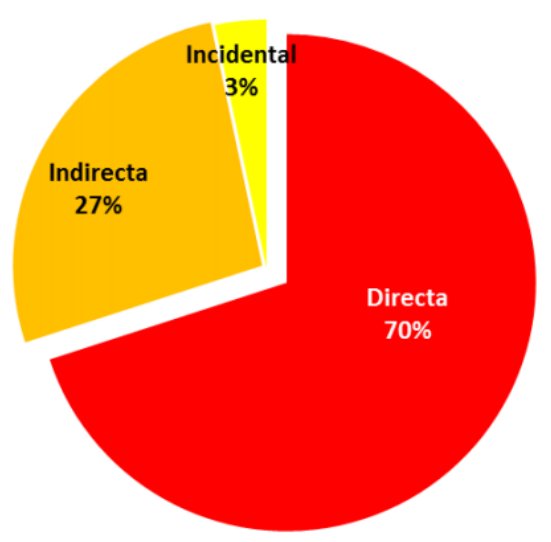

Fuente: Dirección Regional de Salud Piura, 2017 
Según se muestra en la Figura 1.7, las principales causas de muerte materna en la región Piura son de tipo directo con un total de 21 causas diversas. (DIRESAPIURA, 2017).

Figura 1.7

Región Piura: muertes maternas según causa, año 2017

REGION PIURA: MUERTES MATERNAS SEGÚN CAUSA. AÑO 2017

\begin{tabular}{|c|c|c|c|c|}
\hline Distritos & CAUSA BASICA & Directa & \begin{tabular}{|l|l|} 
Indirecta & Incidental \\
\end{tabular} & Total \\
\hline$\boxminus$ A972 & Dengue severo & & 4 & 4 \\
\hline$\exists B 24 X$ & Enfermedad por virus del SIDA & & 1 & 1 \\
\hline$\Xi C 710$ & Tumor Maligno del Cerebro, Excepto Lobulos y Ventriculos & & 1 & 1 \\
\hline-1616 & Hemorragia Intraencefalica de Localizaciones Multiples & & 1 & 1 \\
\hline$\square \mathrm{M} 328$ & Otras Formas de Lupus Eritematoso Sistemico & & 1 & 1 \\
\hline$\Xi 0021$ & Aborto retenido & 2 & 2 & 2 \\
\hline$\boxminus 0064$ & Aborto no Especificado, Incompleto, sin Complicacion & 1 & 1 & 1 \\
\hline$\square 0080$ & Aborto retenido y shock septico & 1 & 1 & 1 \\
\hline$\square 0100$ & Hipertension Esencial Preexistente que Complica el Embarazo & 2 & 2 & 2 \\
\hline-0142 & Síndrome HELLP & 3 & 3 & 3 \\
\hline-0150 & Eclampsia en el Embarazo & 2 & 2 & 2 \\
\hline$\Xi 0152$ & Eclampsia en el Puerperio & 3 & 3 & 3 \\
\hline$\boxminus 0459$ & Desprendimiento prematuro de placenta sin otra especificacion & 1 & 1 & 1 \\
\hline$\Xi 0720$ & hemorragia postparto, tercer periodo & 2 & 2 & 2 \\
\hline$\Xi 0722$ & Hemorragia Postparto Secundaria o Tardia & 3 & 3 & 3 \\
\hline$\square 0730$ & Retencion de la Placenta sin Hemorragia & & 1 & 1 \\
\hline$\boxminus \mathbf{X 6 8 9}$ & $\begin{array}{l}\text { Envenenamiento autoinfligido intencionalmente pore y exposicion a plaguicidase en } \\
\text { lugar no especificado }\end{array}$ & & 1 & 1 \\
\hline Total & & 2. & 8 & 30 \\
\hline
\end{tabular}

Fuente: Dirección Regional de Salud Piura, 2017

Basada en el estudio de la Dirección Regional de Salud de Piura, se ha elegido el distrito de Huancabamba, ubicado en la provincia de Huancabamba, ya que presentó 3 casos de muerte materna en el año 2017 (DIRESAPIURA, 2017).

De acuerdo a la información obtenida en los Principales Indicadores Departamentales 2009 - 2016 del Instituto Nacional de Estadística e Informática INEI, la población del distrito de Huancabamba presenta 1 caso de muerte materna por cada 5074 mujeres, a diferencia del distrito de Pariñas (provincia de Talara) que teniendo también 3 casos de muerte materna en el año 2017, presenta 1 caso de muerte por cada 15038 mujeres, siendo éste de menor proporción. (Anexo 4) (Instituto Nacional de Estadística e Informática, 2017). Esta justificación también se puede visualizar a través de la Figura 1.8 
Figura 1.8

Mapa distrital de muerte materna 2017. Región Piura

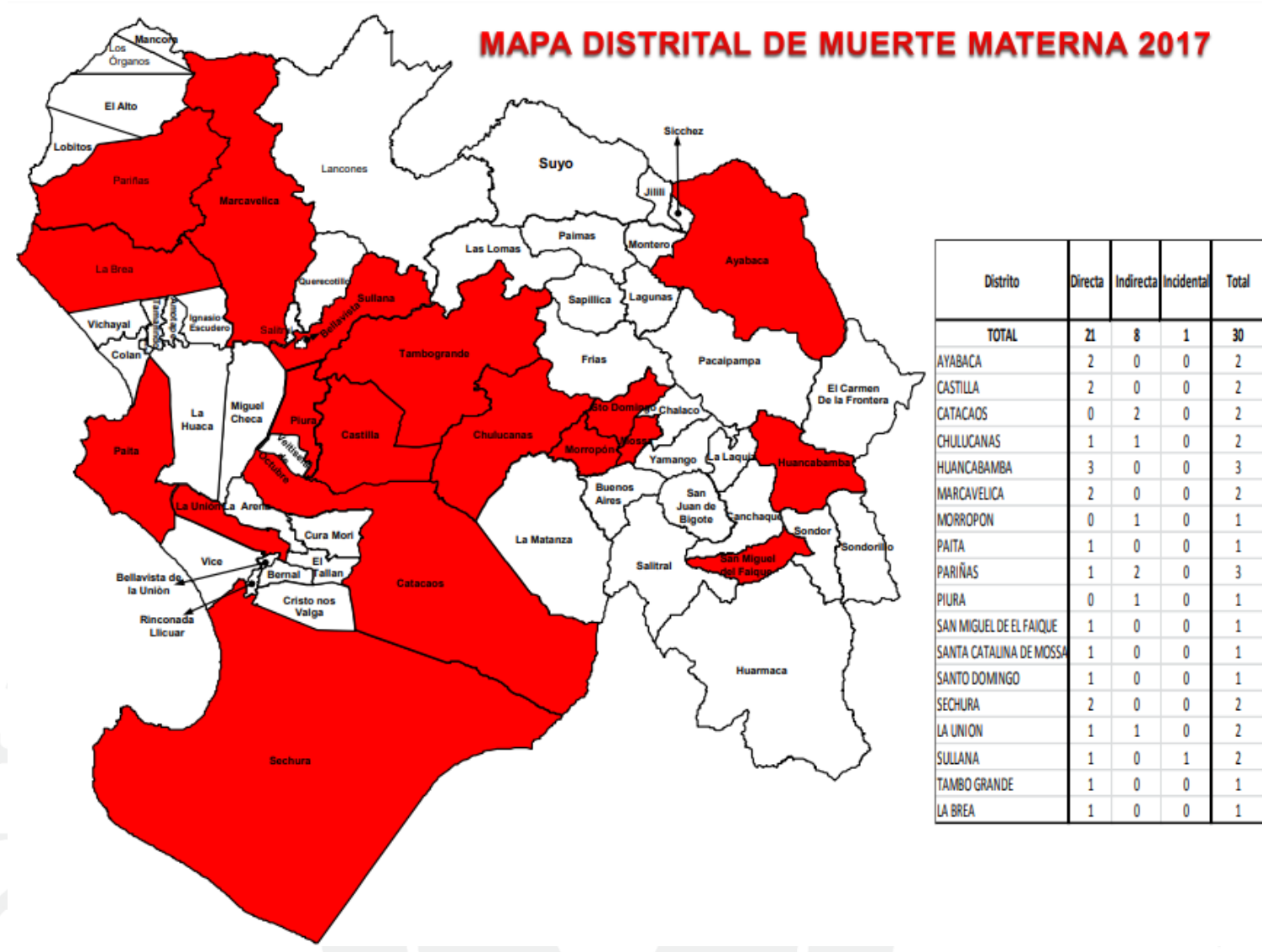




\subsubsection{Organismo: Cáritas del Perú}

Este diagnóstico se presenta bajo la perspectiva de Cáritas del Perú, el cual es un organismo de la Iglesia Católica fundado en 1955 por la Conferencia Episcopal Peruana con el objetivo de promover e incentivar programas en beneficio de las poblaciones más vulnerables y facilitar su desarrollo humano integral.

Cáritas del Perú se despliega a través de 47 Cáritas Diocesanas, lo cual se muestra en la Figura 1.9. (Cáritas del Perú, 2017)

Figura 1.9

Red de Cáritas Diocesanas

\section{RED DE CÁRITAS DIOCESANAS}

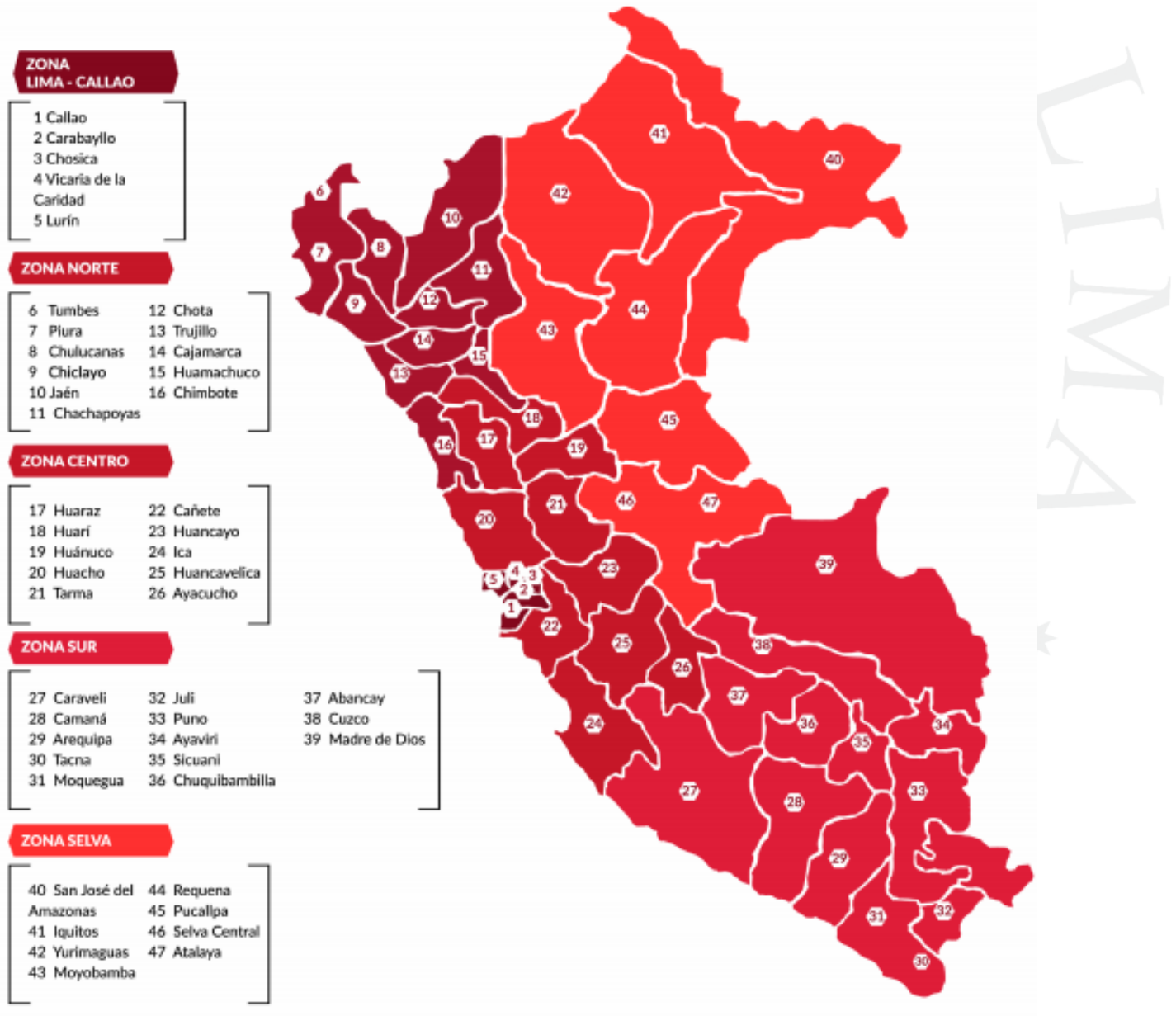

Se ha elegido trabajar desde la mirada de Cáritas del Perú, ya que tiene objetivos dirigidos hacia la promoción del desarrollo de los pueblos y comunidades alejadas del país, dando preferencia a las zonas más pobres de la población, carentes de salud, educación, sistema de agua potable, saneamiento y vías de comunicación; así como la 
capacitación de hombres y mujeres en situaciones vulnerables con la finalidad de que puedan desarrollarse adecuadamente como agentes de cambio y no solo sean asistidos por programas sociales.

La prioridad de Cáritas del Perú, son las personas más vulnerables tales como las mujeres gestantes y lactantes, los niños y niñas que viven en las zonas más pobres del país, así como a los campesinos de zonas rurales, social y económicamente discriminados.

Se tiene como finalidad, poder reducir la exclusión social a través del elevamiento del nivel de participación de los jóvenes y mujeres como líderes de gestión social en beneficio de sus familias y comunidades. Estas labores se realizan a través el diseño, planificación, elaboración, monitoreo y evaluación de programas y proyectos que son realizados por la Red Cáritas.

Asimismo, los proyectos que se realizan están divididos en: categorías de salud y educación (proyecto de salud y nutrición, agua y saneamiento básico, inclusión social, educación), cadenas productivas (proyectos agrícolas, proyectos pecuarios, proyectos agroindustriales), gestión de riesgo y reconstrucción (proyectos de emergencia y gestión de riesgo), y medio ambiente (proyecto de medio ambiente). 


\section{CAPÍTULO II: ESTRATEGIA DE COMUNICACIÓN}

\subsection{Herramientas de Comunicación}

Como parte de la estrategia de Comunicación para esta campaña, se contará con el apoyo logístico de Cáritas Chulucanas y de la Municipalidad Distrital de Huancabamba; para el financiamiento del proyecto se contará con el apoyo de Cáritas Española, quien viene colaborando en proyectos de ayuda humanitaria, cooperación al desarrollo y servicios sociales en la zona norte del país.

Para el público objetivo primario, es decir las mujeres gestantes del distrito de Huancabamba de la provincia de Huancabamaba de la región de Piura, se elaborará específicamente un volante con recomendaciones específicas y signos de alarma que toda gestante debe saber identificar, así como un control de las visitas que recibirá por parte de las educadoras comunales, este control de visitas tiene como finalidad monitorear a la gestante durante la etapa de su embarazo y puerperio; lo manejara la educadora comunal para su control.

La elaboración y difusión del afiche del pre lanzamiento de la campaña, del spot radial, estarán dirigidos tanto al público objetivo primario como secundario, es decir esposo, pareja o familiar cercano de la gestante, estás herramientas de comunicación tienen como finalidad servir de canal para la difusión de la reunión de pre lanzamiento de la campaña en la cual, las madres gestantes podrán empadronarse en la base de datos para recibir capacitación y atención personalizada por parte de la educadoras comunales durante la etapa de su embarazo y puerperio; y en donde también las madres que no son gestantes puedan empadronarse como educadoras comunales para recibir 4 sesiones de capacitaciones y posteriormente realicen intervenciones con las gestantes de tipo puerta a puerta.

La realización y difusión de piezas gráficas y videos en redes sociales, están dirigido al público en general y posibles aliados para una campaña posterior. Estos se publicarán durante el inicio, proceso y al término de la campaña, con la finalidad de dar a conocer los pasos diseñados para obtener el cambio de comportamiento del público primario y cumplir con el objetivo de la campaña. 


\subsubsection{Objetivos}

El objetivo general de esta campaña es contribuir en la concientización de salud y nutrición durante la etapa de embarazo, parto y puerperio de las mujeres gestantes del distrito de Huancabamba, de la provincia de Huancabamba, de la región Piura.

El objetivo específico es educar a través de la comunicación interpersonal a las madres gestantes para contribuir con la reducción la mortalidad materna durante la etapa de embarazo, parto y puerperio en el distrito de Huancabamba, de la provincia de Huancabamba, de la región Piura en un periodo de un año.

Cabe indicar que en esta campaña el público primario es medible; es dirigido, porque se cuenta con un público objetivo primario; es alcanzable, pues con la colaboración de los aliados se puede lograr el objetivo específico de la campaña; es específica en el tiempo por los meses que durarán esta campaña.

El mensaje fuerza de esta campaña es "La muerte materna sí se puede evitar", el cual tiene un lenguaje claro y directo que es comprendido por el público en general.

Las estrategias de comunicación que se realizarán en esta campaña serán: la incidencia mediante la generación de alianzas estratégicas a través de reuniones de trabajo dirigido a los aliados; la comunicación interpersonal mediante la intervención puerta a puerta dirigido al público objetivo primario; y la comunicación masiva mediante la difusión de afiches, volantes, spot de radio dirigido al público objetivo primario y secundario y la elaboración de video y publicaciones en redes sociales dirigido a los aliados y público en general.

Las herramientas en cuanto a incidencia será un trabajo conjunto con los líderes comunales para convocar a una reunión en donde asistan mujeres gestantes, su esposo, conviviente o familiar más cercano para dar a conocer la campaña que se realizará en la comunidad.

En cuanto a comunicación interpersonal, esta se realizará a través de las educadoras comunales, quienes son mujeres voluntarias y representantes de la comunidad que serán capacitadas y monitoreadas adecuadamente para lograr una comunicación plena y eficaz con el público objetivo de la zona. 
En comunicación masiva, en el aspecto gráfico se elaborarán un conjunto de piezas gráficas como afiches y volantes de la campaña dirigidos, los cuales serán distribuidos en zonas estratégicas.

En comunicación audiovisual, se realizará la producción de un spot de radio de 30 segundos dirigido al público primario y secundario para su difusión en medios locales.

En redes sociales, se elaborarán piezas para dar visibilidad al proyecto que realiza Cáritas del Perú junto a Cáritas Chulucanas y Cáritas Española.

\subsubsection{Actividades}

Las actividades que se realizarán como parte de la estrategia de comunicación son el spot radial de 38 segundos, que se difundirá a través de la radio una vez por día durante una semana, en este se indicará las fechas de las reuniones del pre lanzamiento de la campaña, la hora y el lugar, con la finalidad que el público objetivo asista; la difusión de afiches en los mercados, bodegas, colegios, iglesias, postas médicas y municipalidad, en el cual se mencionará el nombre de la campaña, el mensaje fuerza; así como las fechas, hora y el lugar de la reunión.

Se realizarán dos reuniones de pre lanzamiento de la campaña los días viernes 16 de noviembre y sábado 17 de noviembre a las 9:00 en la Municipalidad Distrital de Huancabamba; se ha elegido viernes y sábado para que las madres gestantes y mujeres en general tengan más opciones para asistir a dicha reunión. En estas reuniones se dará a conocer sobre el objetivo de la campaña y el método a utilizar; asimismo, se realizarán dos empadronamientos, uno dirigido a las madres gestantes que desean recibir asistencia técnica durante su embarazo y otro dirigido a las mujeres que desean recibir capacitación para formar parte de la red de educadoras comunales (EC).

El empadronamiento como educadoras comunales (EC), está dirigido a mujeres voluntarias y líderes que conforman la comunidad que en su mayoría tiene la experiencia de ser madres y tienen la capacidad de entablar lazos de confianza como estrategia de la comunicación interpersonal.

La capacitación a las educadoras comunales (EC) se realizará en una jornada de dos horas, una vez a la semana durante un mes, en el cual se les indicará las funciones y 
tareas que deben realizar para cumplir con el objetivo específico de la campaña; además obtendrán un pago mensual como incentivo y monitoreo permanente por parte del personal de Cáritas Chulucanas para evaluar los avances de la campaña.

La intervención puerta a puerta con la comunidad, la realizarán las educadoras comunales una vez al mes; ellas se dividirán por zonas y la asignación de las madres gestantes será permanente para lograr entablar lazos de confianza. Las Educadoras Comunales conversarán directamente con la gestante para realizarle un examen básico en el que consiste la toma de presión, peso corporal, corroborar a través de su cartilla prenatal si se encuentra asistiendo a sus controles; así como una ficha que la Educadora Comunal manejará de forma interna con información que la mujer gestante le proporcionará (Anexo 5).

Finalmente, Cáritas del Perú, a través de su plataforma de Facebook, que cuenta con 43.439 me gusta y 43.080 seguidores, Twitter con 2.644 seguidores e Instagram con 1.048 seguidores, YouTube con 393 suscriptores, difundirá piezas gráficas y audiovisuales adaptadas para cada plataforma sobre el inicio, proceso y término de la campaña, con la finalidad de dar a conocer a más personas y organizaciones nacionales e internacionales sobre la labor humana que se realiza junto a las comunidades. 


\section{CAPÍTULO III: CONCEPTO CREATIVO}

\subsection{Campaña}

Para el concepto creativo, se ha elegido como nombre para la campaña "Madres más fuertes", el cual significa que todas las mujeres gestantes tienen el derecho a estar informadas adecuada y oportunamente para tener un embarazo, parto y puerperio libre de riesgos y así evitar más muertes maternas.

Las propuestas son la elaboración de un afiche informativo, un volante con información y recomendaciones, un spot de radio informativo para la comunidad, piezas graficas como fotopost para Facebook, twitter e Instagram, y la elaboración de un video para el canal de youtube.

\subsubsection{Afiche}

Se elaborará el diseño de un afiche full color por una cara de $50 \mathrm{~cm}$ x $70 \mathrm{~cm}$ en papel couche de 150 gramos.

El afiche, contendrá la imagen de una mujer gestante y de otra mujer con un fichero en la mano en la puerta de una casa, en la imagen se mostrará que están conversando cordialmente; al pie del afiche contendrá el logo de Cáritas del Perú, página web, los logos de las plataformas y el número de Cáritas Chulucanas para mayor información. En la cabecera del afiche se tendrá el nombre de la campaña junto al mensaje fuerza; así como las fechas, hora y lugar de las reuniones.

\subsubsection{Volante}

Se elaborará el diseño de un volante full color por ambas caras de tamaño A5 (14.85 cm x $21 \mathrm{~cm}$ ) en papel couche de 115 gramos.

En la cara del volante se tendrá la misma imagen del afiche, solo que adaptado para una medida de A5, es decir la imagen de una mujer gestante y de otra mujer con un 
fichero en la mano en la puerta de una casa, en la imagen se mostrará que están conversando cordialmente; al pie del volante contendrá el logo de Cáritas del Perú, página web, los logos de las plataformas y el número de Cáritas Chulucanas para mayor información. En la cabecera del volante se tendrá el nombre de la campaña junto al mensaje fuerza.

En la contracara del volante se tendrá la imagen de la educadora comunal y recomendaciones claves para tener un embrazo sano, así como signos de alerta durante la gestación. Este material será distribuido durante el lanzamiento de la campaña en el local comunal y durante las intervenciones de puerta a puerta.

\subsubsection{Spot Radial}

Se realizará la producción de un spot de radio de 30 segundos para la difusión en radios locales.

Guión:

"Mamita huancabambina, acércate este viernes 16 y sábado 17 de noviembre a las 09:00 am al local municipal para informarte acerca de los cuidados necesarios para tener un embarazo sano; y si no estás gestando, también puedes acudir para formar parte de la red de educadoras comunales. Recuerda, este viernes 16 y sábado17 de noviembre a las 9:00 am en el local municipal de Huancabamba, Cáritas del Perú, Transformando Vidas".

\subsubsection{Post}

El Post será una imagen real durante una intervención de puerta a puerta en la comunidad, junto al nombre de la campaña, el logo de Cáritas del Perú y colores institucionales. La imagen estará acompañada de la siguiente descripción "Cáritas del Perú, Cáritas Chulucanas y Cáritas Española en beneficio de la salud materna”.

Este post se adaptará a las medidas de cada plataforma web, para Facebook la imagen cuadrada tendrá 1200 x 1200 px, en Twitter la medida será de 1024 x 512 px y para Instagram será de 1080 x 1080 px. 


\subsubsection{Video}

El video será de 3 minutos, con imágenes cortas de las reuniones en donde se hizo el lanzamiento de la campaña, la capacitación a las educadoras comunales, la intervención puerta a puerta e imágenes de las gestantes asistiendo a sus controles; así como pequeñas declaraciones de las mujeres intervenidas en donde manifiesten su perspectiva al término del proyecto. El formato para ese video que estará en la plataforma de YouTube, será de 1200 x 720 px.

\subsection{Estrategia de Contenidos}

El objetivo del afiche será informar sobre las reuniones de pre lanzamiento de campaña que se brindará en la Municipalidad del distrito de Huancabamba, la idea central del afiche será impactar en el mensaje fuerza de la campaña "La muerte materna sí se puede prevenir", resaltando la hora y el lugar de las reuniones.

La finalidad del volante será recodar a las gestantes las recomendaciones básicas y los signos a alarma que se deben de tener durante el tiempo de embarazo y puerperio, la idea central será el mensaje fuerza de la campaña "La muerte materna sí se puede prevenir" y las recomendaciones.

Para el spot radial, el objetivo será difundir masivamente, las reuniones que se brindarán en la Municipalidad del distrito de Huancabamba a las 9:00 am, la idea central será informar al inicio y al final del spot la fecha, hora y lugar de la reunión. De acuerdo a la Figura 3.1, el spot radial se difundirá en horario de la mañana a través de Radio Exitosa ya que se transmite desde la ciudad de Huancabamba y tiene mayor aceptación con la población. (Radio en América Latina, s.f.) 
Figura 3.1

Radios FM en Piura, Perú

\section{Radios en FM en Piura, Perú}

\begin{tabular}{|c|c|c|c|c|c|c|}
\hline $\mathrm{MHz}$ & Emisora & trasmite desde & kW & web & social & escucha \\
\hline 88.70 & Radio Revelación & Chulucanas & & (2) & $\begin{array}{l}f \\
y\end{array}$ & 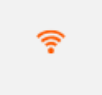 \\
\hline 88.70 & Radio Onda Cero & Piura & 1 & (2) & $\begin{array}{l}f \\
y\end{array}$ & ฐิ \\
\hline 89.30 & Exitosa & Paita & 0.25 & (2) & $\begin{array}{l}\text { ff } \\
\text { ff } \\
y \\
y\end{array}$ & ฐ \\
\hline 90.50 & Exitosa & Huancabamba & & (2) & $\begin{array}{l}f \\
f \\
y \\
y\end{array}$ & ล \\
\hline 90.70 & Radio Moda & Máncora & & (2) & $\begin{array}{l}f \\
y\end{array}$ & ร \\
\hline
\end{tabular}

La finalidad de hacer difusión al inicio del proyecto a través de post, será informar sobre el objetivo de este y el lugar en donde se realizará. Al finalizar el proyecto la difusión del post tendrá como objetivo brindar información sobre los resultados y la metodología utilizada. La plataforma en donde se realizará la mayor cantidad de publicaciones será Facebook, ya que cuenta con mayor cantidad de seguidores. Como se muestra en la Figura 3.2, estas se realizarán en el horario de 2:00 a 3:00 pm. ya que de acuerdo a las publicaciones realizadas se puede observar que los seguidores del fanpage tienden a estar conectados en el trascurso de esas horas. 
Figura 3.2

Estadística de publicaciones destacadas en Facebook

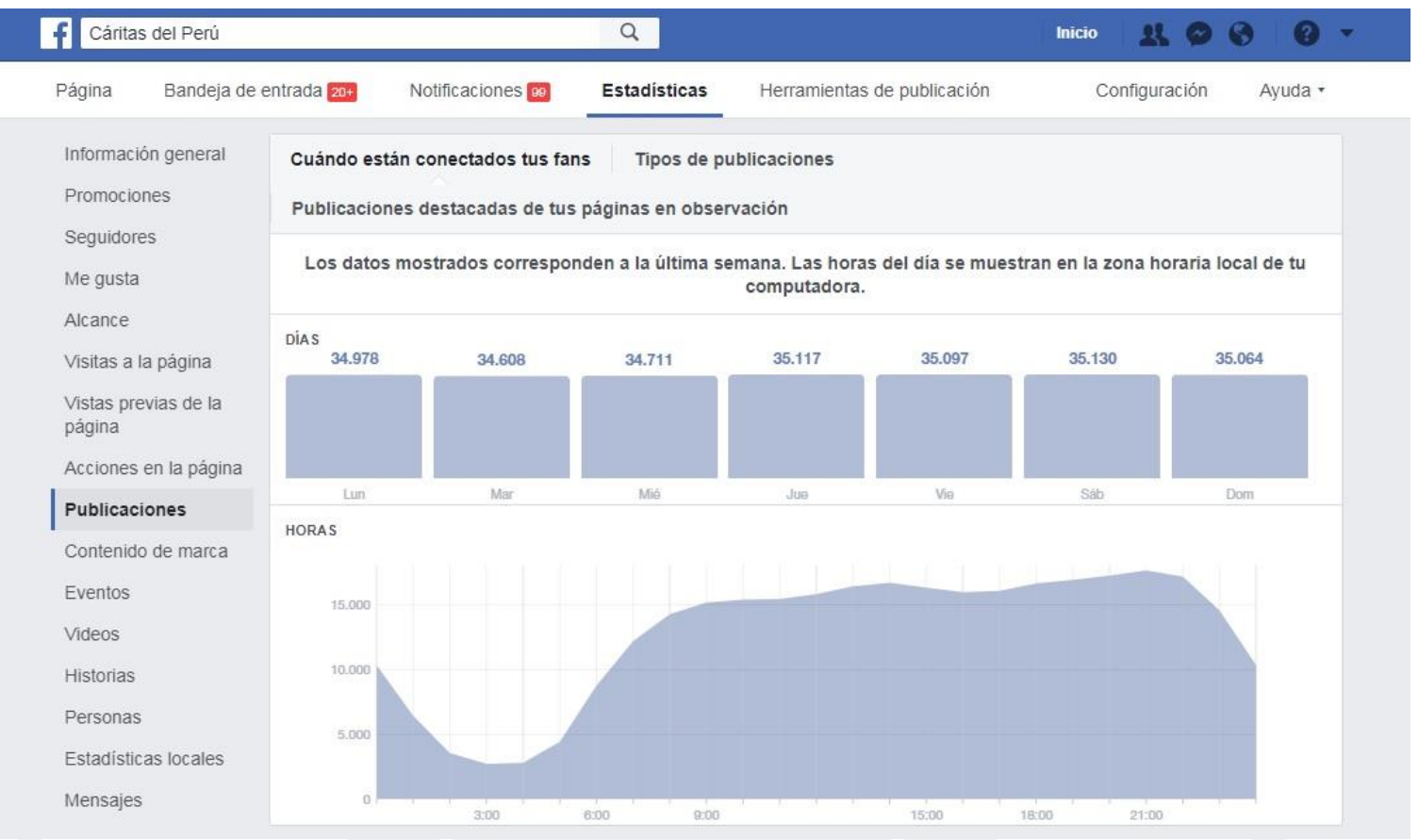

En la difusión del video a través del canal de YouTube el objetivo será dar a conocer sobre el proyecto que se ha realizado en el distrito de Huancabamba, provincia de Huancabamba, región Piura, junto con la colaboración de la Municipalidad del distrito de Huancabamba, Cáritas Chulucanas y Cáritas Española, la idea central será incentivar a que más organizaciones y/o empresas privadas estén dispuestas en apoyar para proyectos futuros en el desarrollo de la población más vulnerable del país. 


\subsection{Plan de Medios}

\subsubsection{Presupuesto}

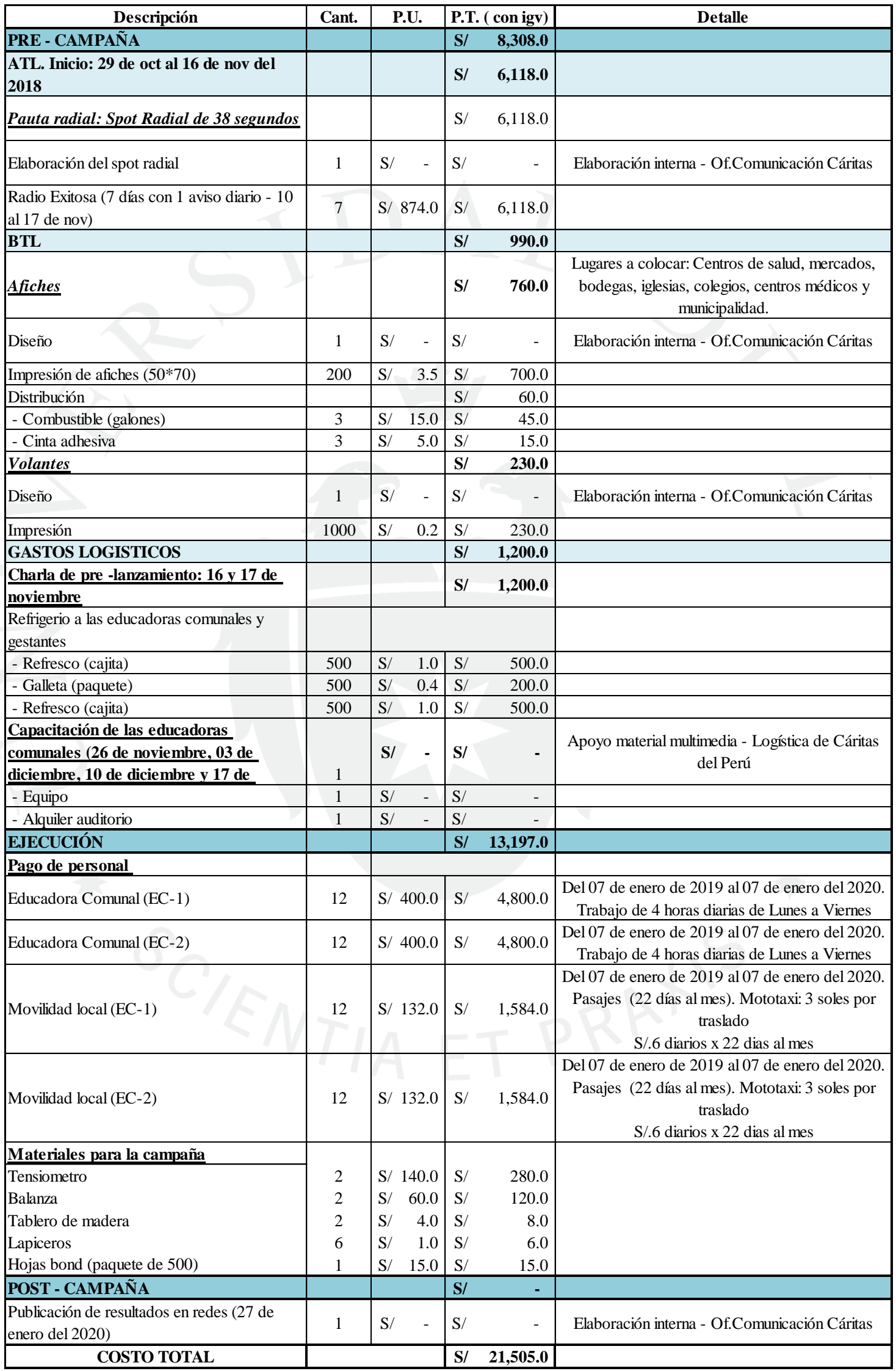


3.3.2 Cronograma de actividades

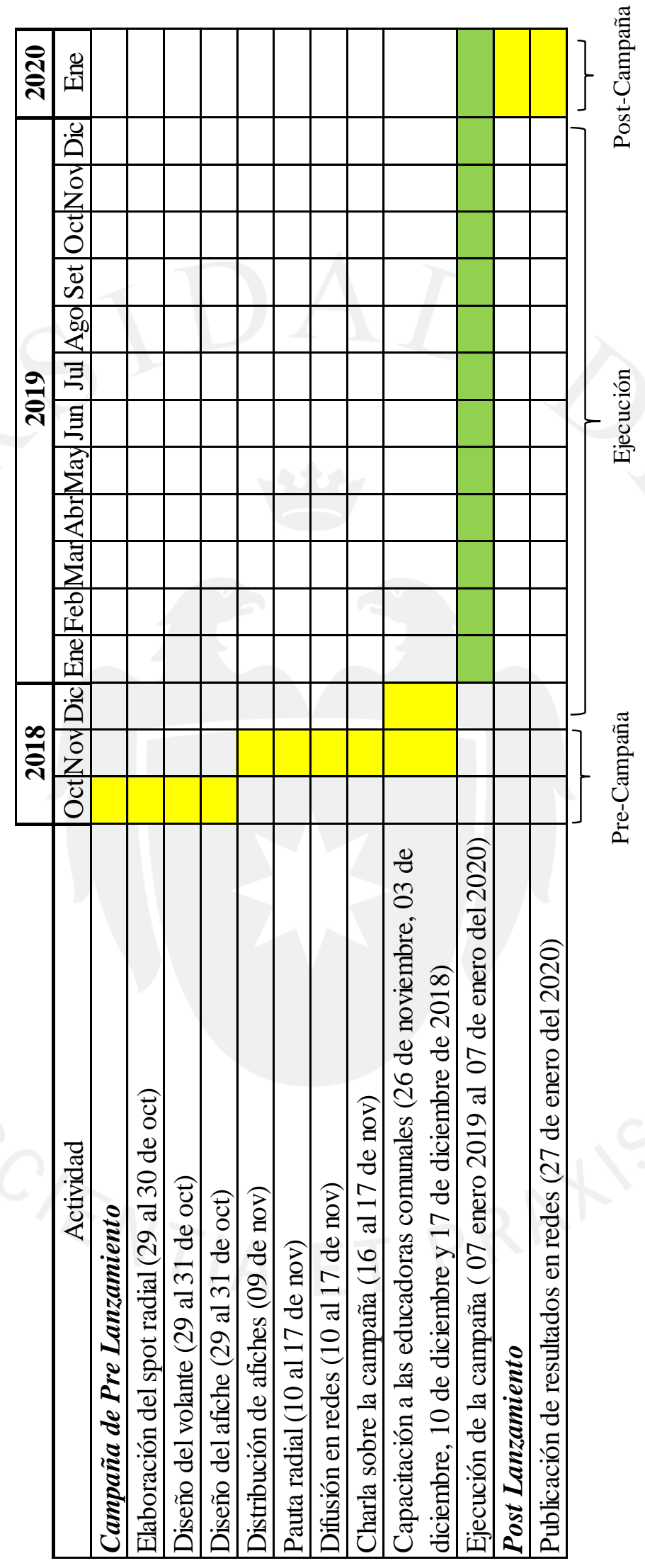




\section{CAPÍTULO IV: EVALUACIÓN}

\subsection{Plan de Evaluación}

El plan de evaluación de la campaña se realizará al término de este. Para evaluar el objetivo específico de la campaña, se tomará como sustento los reportes mensuales obtenidos de las visitas realizadas por parte de las educadoras comunales a las gestantes del distrito de Huancabamba durante las intervenciones de puerta a puerta.

Los indicadores a evaluar serán:

- Cantidad de madres gestantes empadronadas al inicio de la campaña.

- Cantidad de madres gestantes que optaron por no recibir más visitas por parte de las educadoras comunales

- Cantidad de madres gestantes que asistieron a más de cinco controles mensuales.

- Cantidad de madres gestante que asistieron a emergencia ante un signo de alarma.

- Cantidad de madres que se encontraron en el rango peso apropiado durante la etapa de embarazo.

- Cantidad de madres gestantes que presentaron riesgo directo durante la etapa del embarazo (hemorragia, hipertensión, sepsis, etc).

- Cantidad de madres gestantes que pudieron controlar un riesgo indirecto durante la etapa del embarazo.

Asimismo, para evaluar el trabajo de las educadoras comunales, el personal de Cáritas Chulucanas, realizarán una visita a las madres gestantes empadronadas para recoger testimonios y comprobar si la intervención de puerta a puerta fue la más efectiva.

Al término de la campaña, se realizará un informe final sobre los objetivos planteados, las metas alcanzadas y las lecciones aprendidas. 


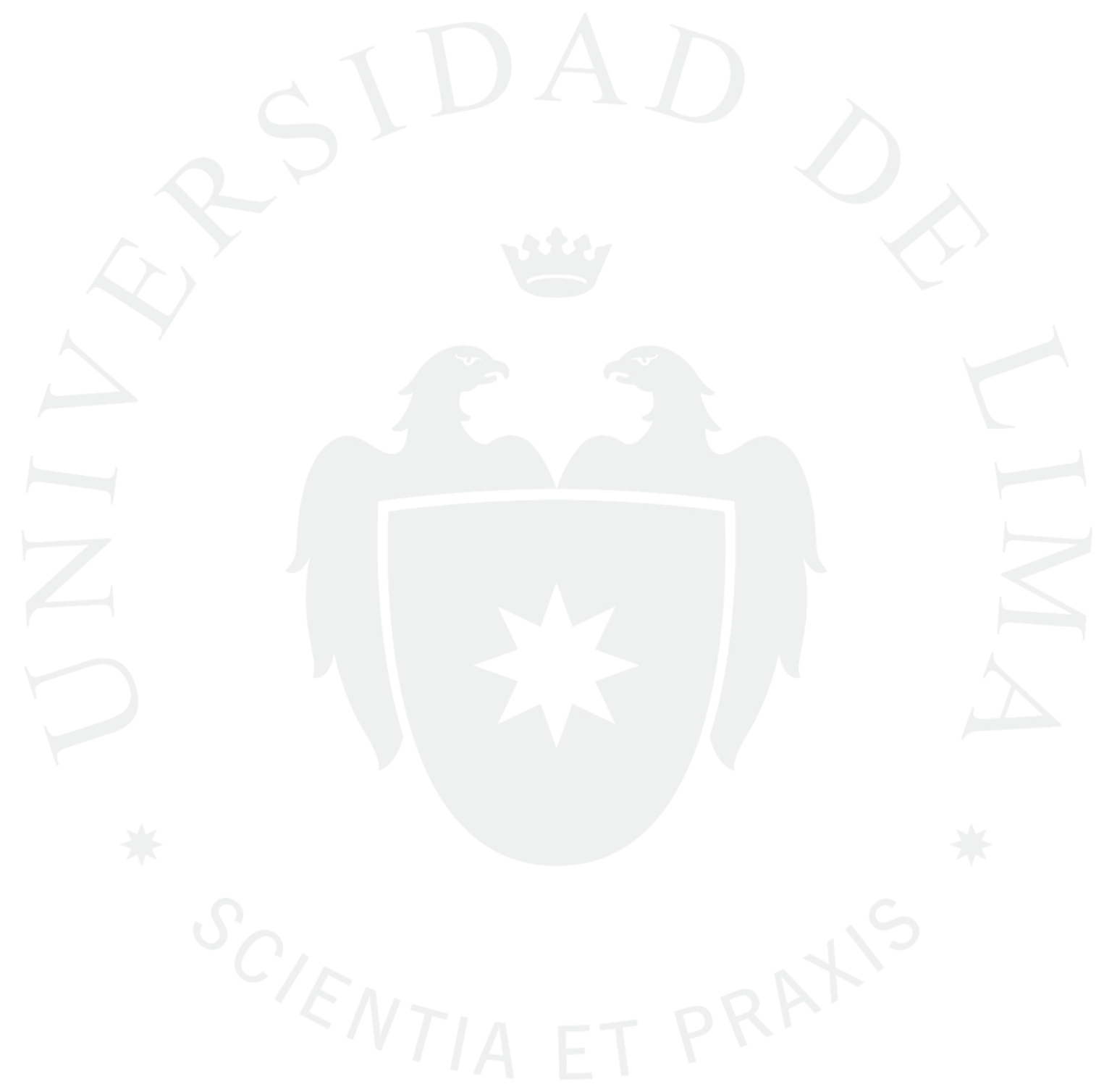




\section{REFERENCIAS}

Cáritas del Perú. (2017). Cáritas del Perú. Obtenido de Cáritas del Perú:

http://www.caritas.org.pe/documentos/balances/BALANCE\%202017\%20_Carit as.pdf

Cáritas del Perú. (s.f.). Cáritas del Perú. Obtenido de Cáritas del Perú: http://www.caritas.org.pe/ac_qs_directorio_de_caritas.html

DIRESAPIURA. (2017). Dirección Regional de Salud Piura. Obtenido de Dirección Regional de Salud Piura:

https://diresapiura.gob.pe/documentos/Mortalidad/MORTALIDADMATERNA 2017.pdf

INEI. (2017). Perú-Encuesta Demográfica y de Salud Familiar-ENDES 2017, Nacional y Departamental. Lima.

Instituto Nacional de Estadística e Informática. (marzo de 2017). Instituto Nacional de Estadística e Informática. Obtenido de Instituto Nacional de Estadística e Informática:

https://drive.google.com/file/d/1Cz_kPWJU9Akb9hHdLxB_E2tBud6RKeml/vie $\mathrm{w}$

Ministerio de Salud . (s.f.). Biblioteca Virtual en Salud. Obtenido de Biblioteca Virtual en Salud: http://bvs.minsa.gob.pe/local/MINSA/1015_OGE74.pdf

Ministerio de Salud. (enero de 2016). Centro Nacional de Epidemiologia, Prevencion y Control de Enfermedades. Obtenido de Centro Nacional de Epidemiologia, Prevencion y Control de Enfermedades:

http://www.dge.gob.pe/portal/docs/vigilancia/boletines/2016/04.pdf

Ministerio de Salud. (2018). Centro Nacional de Epidemiologia, Prevencion y Control de Enfermedades. Obtenido de Centro Nacional de Epidemiologia, Prevencion y Control de Enfermedades:

http://www.dge.gob.pe/portal/docs/vigilancia/sala/2018/SE02/mmaterna.pdf

OMS. (16 de Febrero de 2018). Organización Mundial de la Salud. Recuperado el 14 de setiembre de 2018, de Organización Mundial de la Salud:

http://www.who.int/es/news-room/fact-sheets/detail/maternal-mortality

Organización Mundial de la Salud. (16 de febrero de 2018). Organización Mundial de la Salud. Obtenido de Organización Mundial de la Salud:

http://www.who.int/es/news-room/fact-sheets/detail/maternal-mortality

Radio en América Latina. (s.f.). Radio en América Latina. Obtenido de Radio en

América Latina: https://radio-america-

latina.org/fm/fm.php?itu=Per\%FA\&region=piu

UNESCO. (2017). Organización de las Naciones Unidas para la Educación, la Ciencia y la Cultura. Obtenido de Organización de las Naciones Unidas para la Educación, la Ciencia y la Cultura:

http://www.unesco.org/new/es/culture/achieving-the-millennium-developmentgoals/mdgs/ 
ANEXOS 
Anexo 1. Causa básica de muerte materna clasificada como directa, año 2015

\begin{tabular}{|c|c|c|}
\hline Causas Básicas de muerte materna directa & $\mathrm{N}^{0}$ & $\%$ \\
\hline Hemorragia & 66 & $36.7 \%$ \\
\hline \begin{tabular}{|l|l} 
& Otras inercias uterinas \\
\end{tabular} & 12 & $6.7 \%$ \\
\hline Hemorragia del tercer periodo del parto & 12 & $6.7 \%$ \\
\hline Otras hemorragias postparto inmediatas & 7 & $3.9 \%$ \\
\hline Embarazo ectópico & 7 & $3.9 \%$ \\
\hline Placenta previa & 6 & $3.3 \%$ \\
\hline Hemorragia postparto secundaria o tardía & 4 & $2.2 \%$ \\
\hline Transtorno de la placenta, no especificado & 2 & $1.1 \%$ \\
\hline Ruptura del útero durante el trabajo de parto & 2 & $1.1 \%$ \\
\hline Inversión del útero, postparto & 2 & $1.1 \%$ \\
\hline Choque hipovolémico & 2 & $1.1 \%$ \\
\hline Aborto espontáneo complicado por hemorragia excesiva o tardía & 2 & $1.1 \%$ \\
\hline Hemorragia intraparto, no especificada & 1 & $0.6 \%$ \\
\hline Hematoma de hrida quirúrgica obstétrica & 1 & $0.6 \%$ \\
\hline Desprendimiento prematuro de la placenta, sin otra especificación & 1 & $0.6 \%$ \\
\hline Desgarro vaginal obstétrico alto & 1 & $0.6 \%$ \\
\hline Desgarro obstétrico del cuello uterino & 1 & $0.6 \%$ \\
\hline Lesión de órganos o tejidos de la pelvis consecutivo al aborto, al embarazo ectópico y al embarazo molar & 1 & $0.6 \%$ \\
\hline Embarazo abdominal & 1 & $0.6 \%$ \\
\hline \begin{tabular}{|l|l|} 
Hemorragia vaginal y uterina anormal, no especificada \\
\end{tabular} & 1 & $0.6 \%$ \\
\hline Enfe rme dad Hipertensiva del embarazo & 57 & $31.7 \%$ \\
\hline \begin{tabular}{|l|l|} 
& Preclampsia severa \\
\end{tabular} & 23 & $12.8 \%$ \\
\hline Eclampsia en el embarazo & 10 & $5.6 \%$ \\
\hline Eclampsia en el puerperio & 7 & $3.9 \%$ \\
\hline Eclampsia, en el periodo no especificado & 3 & $1.7 \%$ \\
\hline Hipertensión gestacional (incluida por el embarazo) & 3 & $1.7 \%$ \\
\hline Hipertensión materna, no especificada & 2 & $1.1 \%$ \\
\hline Hipertensión esencial preexistente que complica el embarazo, el parto y el puerperio & 2 & $1.1 \%$ \\
\hline Síndrome de Hellp & 2 & $1.1 \%$ \\
\hline Eclampsia durante el trabajo de parto & 1 & $0.6 \%$ \\
\hline Preclampsia moderada & 1 & $0.6 \%$ \\
\hline Hemorragia subaracnoidea, no especificada & 1 & $0.6 \%$ \\
\hline Hemorragia subaracnoidea de arteria intracraneal no especificada & 1 & $0.6 \%$ \\
\hline Accidente vascular encefálico agudo, no especificado como hemorrágico o isquémico & 1 & $0.6 \%$ \\
\hline
\end{tabular}




\begin{tabular}{|c|c|c|}
\hline Causas Básicas de muerte materna directa & $\mathbf{N}^{0}$ & $\%$ \\
\hline Sepsis & 38 & $21.1 \%$ \\
\hline Retención de la placenta & 5 & $2.8 \%$ \\
\hline Retención de fragmentos de la placenta o de las membranas & 5 & $2.8 \%$ \\
\hline Aborto no especificado complicado con infección genital y pelviana & 5 & $2.8 \%$ \\
\hline Sepsis Puerperal & 4 & $2.2 \%$ \\
\hline Aborto retenido & 4 & $2.2 \%$ \\
\hline Ruptura prematura de las membranas & 3 & $1.7 \%$ \\
\hline Infección de la bolsa amniótica o de las membranas & 2 & $1.1 \%$ \\
\hline Aborto espontáneo complicado con infección genital o pelviana & 2 & $1.1 \%$ \\
\hline Otro aborto, incompleto, complicado con infeción genital y pelviana & 1 & $0.6 \%$ \\
\hline Otras infecciones y las no especificadas de las vías genitourinarias en el embarazo & 1 & $0.6 \%$ \\
\hline Otras infecciones puerperales especificadas & 1 & $0.6 \%$ \\
\hline Infección no especificada de las vías urinarias en el embarazo & 2 & $1.1 \%$ \\
\hline Infección genital y pelviana consecutiva al aborto, al embarazo ectópico y al embarazo molar & 1 & $0.6 \%$ \\
\hline Septicemia, no especificada & 1 & $0.6 \%$ \\
\hline Aborto no especificado, incompleto, complicado con infección genital y pelviana & 1 & $0.6 \%$ \\
\hline Otros & 19 & $10.6 \%$ \\
\hline Choque durante o después del trabajo de parto y el parto & 3 & $1.7 \%$ \\
\hline Choque consecutivo al aborto, al embarazo ectópico y al embarazo molar & 2 & $1.1 \%$ \\
\hline Coagulación intravascular diseminada (síndrome de desfibrinación) & 2 & $1.1 \%$ \\
\hline Otras complicaciones especificadas del trabajo de parto y del parto & 1 & $0.6 \%$ \\
\hline Trabajo de parto obstruido debido a distocia de hombros & 1 & $0.6 \%$ \\
\hline Trabajo de parto obstruido debido a diesproporción fetpleviana & 1 & $0.6 \%$ \\
\hline Enfermedades del sistema circulatorio que complican el embarazo, el parto y el puerperio & 1 & $0.6 \%$ \\
\hline Anemia que complica el embarazo, el parto y el puerperio & 2 & $1.1 \%$ \\
\hline Aborto espontáneo, incompleto, sin complicaciones & 1 & $0.6 \%$ \\
\hline Contracciones primarias inadecuadas & 2 & $1.1 \%$ \\
\hline Otras formas de choque & 1 & $0.6 \%$ \\
\hline Degeneración grasa del hígado, no clasificada en otra parte & 1 & $0.6 \%$ \\
\hline Choque anafiláctico, no especificado & 1 & $0.6 \%$ \\
\hline
\end{tabular}

Fuente: Sistema Nacional de Vigilancia Epidemiológico en Salud Pública-DGE-MINSA Información preliminar 2015 
Anexo 2. Causa básica de muerte materna clasificada como indirecta, año 2015

\begin{tabular}{|c|c|c|}
\hline Causas Básicas de muerte materna indirecta & $\mathbf{N}^{0}$ & $\%$ \\
\hline Infecciones & 22 & $24.4 \%$ \\
\hline \begin{tabular}{l|l} 
Neumonía no especificada \\
\end{tabular} & 3 & $3.3 \%$ \\
\hline Neumonía bacteriana, no especificada & 3 & $3.3 \%$ \\
\hline Infección de vias urinarias, sitio no especificado & 3 & $3.3 \%$ \\
\hline Tuberculosis miliar, sin otra especificación & 2 & $2.2 \%$ \\
\hline Septicemia, no especificada & 2 & $2.2 \%$ \\
\hline Paludismo debido a Plasmodium vivax con otras complicaciones & 2 & $2.2 \%$ \\
\hline Apendicitis aguda & 2 & $2.2 \%$ \\
\hline Tuberculosis de los intestinos, el peritoneo y los ganglios mesentéricos & 1 & $1.1 \%$ \\
\hline Neumonía debido a adenovirus & 1 & $1.1 \%$ \\
\hline Diarrea y gastroenteritis de presunto origen infeccioso & 1 & $1.1 \%$ \\
\hline Dengue grave & 1 & $1.1 \%$ \\
\hline Bronconeumonía, no especificada & 1 & $1.1 \%$ \\
\hline Lesiones autoinflingida/Violencia/Transtornos de salud mental & 13 & $14.4 \%$ \\
\hline \begin{tabular}{l|l} 
Envenenamiento autoinflingido intencionalmente por, y exposición a plaguicidas, en \\
vivienda
\end{tabular} & 4 & $4.4 \%$ \\
\hline Envenenamiento por efecto tóxico de sustancia no especificada & 2 & $2.2 \%$ \\
\hline $\begin{array}{l}\text { Envenenamiento autoinflingido intencionalmente por, y exposición a otros productos } \\
\text { químicos y sustancias nocivas, y los no especificados, en vivienda }\end{array}$ & 2 & $2.2 \%$ \\
\hline Episodio depresivo, no especificado & 1 & $1.1 \%$ \\
\hline Envenenamiento por insecticidas oranofosforados y carbanatos & 1 & $1.1 \%$ \\
\hline Ahorcamiento, estrangulamiento y sofocación, de intención no determinada, en vivienda & 1 & $1.1 \%$ \\
\hline Lesión autoinflingida intencionalmente por ahorcamiento, estrangulamiento o sofocación & 1 & $1.1 \%$ \\
\hline Transtorno mental orgánico o sintomático, no especificado & 1 & $1.1 \%$ \\
\hline Enfermedad cerebro vascular / Otros del sistema nervioso & 12 & $13.3 \%$ \\
\hline \begin{tabular}{l|l} 
Epilepsia, tipo no especificado \\
\end{tabular} & 2 & $2.2 \%$ \\
\hline Edema cerebral & 2 & $2.2 \%$ \\
\hline Mielitis transversa aguda en enfermedad desmielinizante del sistema nervioso central & 1 & $1.1 \%$ \\
\hline Lesión que ocupa el espacio intracraneal & 1 & $1.1 \%$ \\
\hline Malformación arteriovenenosa de los vasos cerebrales & 1 & $1.1 \%$ \\
\hline Hemorragia subarancoidea, no especificada & 1 & $1.1 \%$ \\
\hline Hemorragia iontraencefálica en cerebr & 1 & $1.1 \%$ \\
\hline Enfermedad cerebrovascular, no especificada & 1 & $1.1 \%$ \\
\hline Encefalopatía no especificada & 1 & $1.1 \%$ \\
\hline \begin{tabular}{l|l} 
Aneurisma de sitio no especificado \\
\end{tabular} & 1 & $1.1 \%$ \\
\hline Enferme dad cardiovas cular & 11 & $12.2 \%$ \\
\hline Insuficiencia cardíaca congestiva & 3 & $3.3 \%$ \\
\hline Transtornos de las válvulas mitral y aórtica & 1 & $1.1 \%$ \\
\hline Otras enfermedades de la válvula mitral & 1 & $1.1 \%$ \\
\hline Malformación congénita del corazón, no especificada & 1 & $1.1 \%$ \\
\hline Choque cardiogénico & 1 & $1.1 \%$ \\
\hline Cardiomiopatía en el puerperio & 1 & $1.1 \%$ \\
\hline Cardiomiopatía dilatada & 1 & $1.1 \%$ \\
\hline Conducto arterioso permeable & 1 & $1.1 \%$ \\
\hline Infarto agudo del miocardio, sin otra especificación & 1 & $1.1 \%$ \\
\hline
\end{tabular}




\begin{tabular}{|c|c|c|}
\hline Causas Básicas de muerte materna indirecta & $\mathbf{N}^{\mathbf{0}}$ & $\%$ \\
\hline Tumores & 7 & $7.8 \%$ \\
\hline \begin{tabular}{l|l} 
Carcinoma de células hepáticas \\
\end{tabular} & 2 & $2.2 \%$ \\
\hline Tumor maligno del estómago, parte no especificada & 1 & $1.1 \%$ \\
\hline Tumor maligno del encéfalo, parte no especificada & 1 & $1.1 \%$ \\
\hline Tumor maligno del cuello del útero, sin otra especificación & 1 & $1.1 \%$ \\
\hline Tumor de comportamiento incierto o desconocido de la glándula tiroides & 1 & $1.1 \%$ \\
\hline Tumor benigno del corazón & 1 & $1.1 \%$ \\
\hline Enfermedades endocrinológicas & 5 & $5.6 \%$ \\
\hline Tirotoxicosis, no especificada & 2 & $2.2 \%$ \\
\hline Tirotoxicosis con bocio difuso & 1 & $1.1 \%$ \\
\hline Diabetes mellitus preexistente insulinoindependiente, en el embarazo & 1 & $1.1 \%$ \\
\hline Crisis o tormenta tirotóxica & 1 & $1.1 \%$ \\
\hline Enfermedades sistema digestivo & 4 & $4.4 \%$ \\
\hline \begin{tabular}{l|l} 
Insuficiencia hepátca aguda o subaguda \\
\end{tabular} & 1 & $1.1 \%$ \\
\hline Cirrosis hepática alcohólica & 1 & $1.1 \%$ \\
\hline Cálculo de la vesícula biliar con otra colecistitis & 1 & $1.1 \%$ \\
\hline \begin{tabular}{|l|} 
Ulcera gástrica, aguda con perforación \\
\end{tabular} & 1 & $1.1 \%$ \\
\hline Otros & 16 & $17.8 \%$ \\
\hline \begin{tabular}{l|l} 
& Púrpura trombocitopénica idiopática \\
\end{tabular} & 2 & $2.2 \%$ \\
\hline Paro respiratorio & 2 & $2.2 \%$ \\
\hline $\begin{array}{l}\text { Muerte que ocurre en menos de } 24 \text { horas del inicio de los síntomas, no explicada de otra } \\
\text { forma }\end{array}$ & 2 & $2.2 \%$ \\
\hline Síndrome del choque tóxico & 1 & $1.1 \%$ \\
\hline Lupus eritematoso sistémico, sin otra especificación & 1 & $1.1 \%$ \\
\hline Insuficiencia respiratoria aguda & 1 & $1.1 \%$ \\
\hline Embolia y trombosis de otras venas especificadas & 1 & $1.1 \%$ \\
\hline Edema pulmonar & 1 & $1.1 \%$ \\
\hline Disección de aorta (cualquier parte) & 1 & $1.1 \%$ \\
\hline Aspiración de líquidos & 1 & $1.1 \%$ \\
\hline Púpura trombocitopénica idiopática & 1 & $1.1 \%$ \\
\hline Anemia posthemorrágica aguda & 1 & $1.1 \%$ \\
\hline Nefritis tubulointesticial aguda & 1 & $1.1 \%$ \\
\hline
\end{tabular}

Fuente: Sistema Nacional de Vigilancia Epidemiológico en Salud Pública-DGE-MINSA Información preliminar 2015 


\section{Anexo 3. Entrevista al Dr. Luis Danckers Peralta, Ginecólogo-Obstetra de INPPARES}

$* * *$

NTH: Nancy Tapia Huambachano

Dr.LD: Dr. Luis Danckers

$* * *$

(Saludo)

NTH: ¿Quisiera saber qué es la mortalidad materna?

Dr.LD:La mortalidad materna se refiere a todas las causas de muerte ocasionadas por un embarazo. Se dice que actualmente la tasa de mortalidad materna ha mejorado mucho en el país. Hace unos 10 o 15 años estábamos arriba de 200 muertes por 100,000 nacidos vivos, hoy día estamos en 68 pero se sabe que el $70 \%$ al $90 \%$ de esas muertes maternas podrían ser prevenibles.

NTH: ¿Y cuáles son las causas principales?

Dr.LD:La principal causa groseramente que cabalga pero así es una forma brutal, es la que se refiere a hemorragia por parto, la principal causa. Como comprenderás estas muertes muchas veces se dan en personas donde hay poco acceso de salud. El parto en casa, que generalmente acompañan estas muertes, nos generan una tremenda dificultad, entonces tenemos que tenerlo en cuenta para esta situación.

NTH: ¿Cuáles son las mujeres más propensas?...las que viven en zonas rurales entonces?

Dr.LD:Una zona es zonas rurales... efectivamente

1. En zonas rurales la tasa es más elevada

2. Mujeres que no tienen control prenatal

3. Partos en casa

NTH: ¿También puede ser la pobreza?

Dr.LD: Yo considero que va de la mano: De la mano porque...... bueno porque es pobreza y educación que van de la mano. Por que si tú no sabes y en tu pueblo siempre te han atendido así tú crees que es lo normal... tú crees que es normal que tengan 7-8 hijos y que se pueden ir muriendo...no es cierto?

La idea es definitivamente tomar medidas que disminuyan esa opción para que no se tenga dificultad a posteriori. 
NTH: Entonces una medida para reducir la MM cuál podría ser?

Dr. LD:

1. La educación

2. Que haya un adecuado acceso de salud que permita hacer el control adecuado prenatal

NTH: ...e informar a las personas de los riesgos?

Dr.LD: Informar de los beneficios - riesgos. Si estando en hospitales A-1 hay riesgos, imagínate en que sea atendido un parto en no las adecuadas consideraciones.

NTH: Y algunas recomendaciones?

Dr.LD:Fundamentalmente:

La mortalidad materna también tiene que ver con el estado de nutrición de cada paciente, entonces adecuada nutrición, educación. Que sea fácil el acceso a postas o servicios de salud, disciplina de la paciente y disciplina del personal de salud en la atención de la paciente, se requiere por lo menos 5 controles durante el embarazo como mínimo, entonces eso te da una pauta a tener en cuenta

NTH: ¿Y también cree que es importante tener el apoyo de la pareja?

Dr.LD:Definitivamente, yo creo que estamos en una época en que la comunicación es muy importante y comunicación va desde tener el apoyo de la persona que está contigo, tu pareja, y si no lo hubiera tener el apoyo de la familia porque de esa manera no vas a entrar en depresión en una situación de tremendo pesar.

NTH: ...Y también el embarazo es más tranquilo para no tener alguna enfermedad

Dr.LD: Claro, disminuyes el stress que son factores que hay que tenerlo en cuenta.

(Despedida) 
Anexo 4. Mortalidad materna y población estimada por sexo, a nivel distrital en el departamento de Piura

\begin{tabular}{|c|c|c|c|c|c|c|}
\hline \multicolumn{2}{|c|}{$\begin{array}{c}\text { Ambito (Cáritas Diocesana / } \\
\text { Provincia/Distrito) }\end{array}$} & $\begin{array}{c}\text { Mortalidad } \\
\text { Mate rna } \\
2017 \\
\text { (DIRESA } \\
\text { Piura) }\end{array}$ & $\begin{array}{l}\text { Población } \\
\text { 2016 } \\
\text { (INEI) }\end{array}$ & $\begin{array}{c}\text { Población } \\
\text { masculina } \\
\text { estimada } \\
(50.2 \%)\end{array}$ & $\begin{array}{c}\text { Población } \\
\text { femenina } \\
\text { estimada } \\
(49.8 \%)\end{array}$ & $\begin{array}{c}\text { Población } \\
\text { estimada de } \\
\text { madres } \\
\text { gestantes } \\
(3.1 \%)\end{array}$ \\
\hline \multicolumn{7}{|c|}{ Cáritas Piura-Tumbes } \\
\hline & TALARA & & & 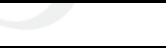 & 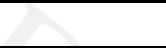 & \\
\hline & \begin{tabular}{|l|l|} 
Pariñas \\
\end{tabular} & 3 & 90,236 & 45,298 & 44,938 & 1,404 \\
\hline & La Brea & 1 & 11,827 & 5,937 & 5,890 & 184 \\
\hline \multicolumn{7}{|c|}{ PIURA } \\
\hline & \begin{tabular}{|l|l|} 
& Castilla \\
\end{tabular} & 2 & 144,826 & 72,703 & 72,123 & 2,254 \\
\hline & Catacaos & 2 & 73,393 & 36,843 & 36,550 & 1,142 \\
\hline & Piura & 1 & 155,241 & 77,931 & 77,310 & 2,416 \\
\hline 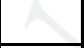 & La Unión & 2 & 41,019 & 20,592 & 20,427 & 638 \\
\hline & Tambogrande & 1 & 120,760 & 60,622 & 60,138 & 1,879 \\
\hline & SULLANA & 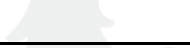 & & & & \\
\hline & \begin{tabular}{|l|} 
Marcavelica \\
\end{tabular} & 2 & 29,034 & 14,575 & 14,459 & 452 \\
\hline & Sullana & 2 & 178,173 & 89,443 & 88,730 & 2,773 \\
\hline \multicolumn{7}{|c|}{ PAITA } \\
\hline & \begin{tabular}{|l|l|} 
& Paita \\
\end{tabular} & 1 & 94,566 & 47,472 & 47,094 & 1,472 \\
\hline \multicolumn{7}{|c|}{ SECHURA } \\
\hline & \begin{tabular}{|l|} 
Sechura \\
\end{tabular} & 2 & 43,525 & 21,850 & 21,675 & 677 \\
\hline \multicolumn{7}{|c|}{ Cáritas Chulucanas } \\
\hline \multicolumn{7}{|c|}{\begin{tabular}{l|l} 
AYABACA \\
\end{tabular}} \\
\hline & \begin{tabular}{|l|} 
Ayabaca \\
\end{tabular} & 2 & 38,506 & 19,330 & 19,176 & 599 \\
\hline \multicolumn{7}{|c|}{ MORROPÓN } \\
\hline & \begin{tabular}{|l|l|} 
Chulucanas \\
\end{tabular} & 2 & 76,224 & 38,264 & 37,960 & 1,186 \\
\hline & Morropón & 1 & 14,116 & 7,086 & 7,030 & 220 \\
\hline & Sta.Catalina de Mossa & 1 & 4,125 & 2,071 & 2,054 & 64 \\
\hline & Santo Domingo & 1 & 7,244 & 3,636 & 3,608 & 113 \\
\hline \multicolumn{7}{|c|}{ HUANCABAMBA } \\
\hline & \begin{tabular}{|l|l} 
Huancabamba \\
\end{tabular} & 3 & 30,564 & 15,343 & 15,221 & 476 \\
\hline & San Miguel de Faique & 1 & 8,996 & 4,516 & 4,480 & 140 \\
\hline
\end{tabular}

Fuente: 1. Indicadores Departamentales al 2016. INEI

2.Situación epidemiológica de vigilancia de muerte materna 2017. DIRESA Piura

Elaboración: Propia, con estimaciones basadas en información de INEI.

Nota: Del total de 65 distritos en el departamento de Piura, existen 18 que presentan registro de mortalidad 


\section{Anexo 5. Ficha de control}

DNI:

Nombre de la educadora comunal: DNI:

Nombre de la madre visitada:

Dirección:

Comunidad: Sector :

Distrito : Huancabamba Provincia : Huancabamba

Región: Piura

Visita Nro.

Peso:

Presión:

Semanas de gestación:

Fecha de su último control prenatal:

Fecha de su próximo control prenatal:

¿Ha ingerido bebidas alcohólicas? SI NO Razón:

¿Ha fumado cigarro?

SI NO Razón:

¿Asistió a atención por emergencia durante el último mes? SI NO

¿Cuál fue la razón, de ser afirmativa la respuesta anterior?

¿Qué tratamiento le brindaron?

¿Concluyó con el tratamiento?

SI

NO / Razón:

¿Sabe identificar signos de riesgo durante el embarazo? SI

$\mathrm{NO}$

¿Sabe qué alimentos y bebidas no son recomendables durante el embarazo? SI

NO

Observaciones:

Fecha de próxima visita:

Fecha:

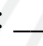

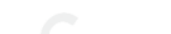

